\title{
PRELIMINARY STUDY OF A RADIANTLY HEATED FLUIDIZED BED FOR THE PRODUCTION OF HIGH PURITY SILICON
}

by

\author{
Octave Levenspiel, Milton Larson, Guo-Tai Zhang and Fan Ouyang \\ Oregon State University \\ Corvallis, OR 97331
}

prepared for

Jet Propulsion Laboratory

California Institute of Technology

Pasadena, CA 91109 
This work was performed for the Jet Propulsion Laboratory, California Institute of Technology, and was sponsored by the United States Department of Energy through an agreement with the National Aeronautics and Space Administration.

This report was prepared as an account of work sponsored by the United States Government. Neither the United States nor the United States Department of Energy, nor any of their employees, nor any of their contractors, subcontractors, or their employees, makes any warranty, expressed or implied, or assumes any legal liability or responsibility for the accuracy, completeness or usefulness of any information, apparatus, product or process disclosed, or represents that its use would not infringe privately owned rights. 


\section{PRELIMINARY STUDY OF A RADIANTLY HEATED FLUIDIZED BED}

FOR THE PRODUCTION OF HIGH-PURITY SILICON

A One-Year Research Project

by

Octave Levenspiel ${ }^{1}$, Milton Larson ${ }^{2}$, Guo-Tai Zhang ${ }^{3}$, and Fan Ouyang ${ }^{4}$

Oregon State University

Corvallis, Oregon 97331

Final Report to Jet Propulsion Laboratory

August 1983

Page

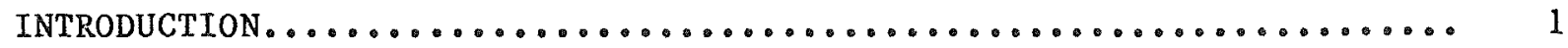

EXPERIMENTAL......................................... 4

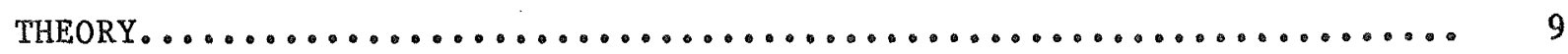

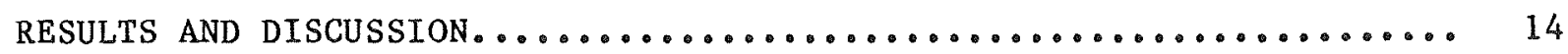

SUMMARY OF EXPERIMENTAL FINDINGS AND THEIR RELEVANCE IN SCALE-UP..... 31

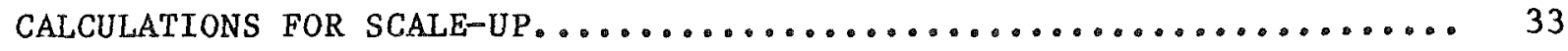

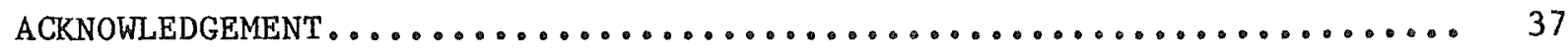

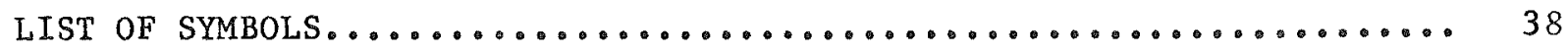

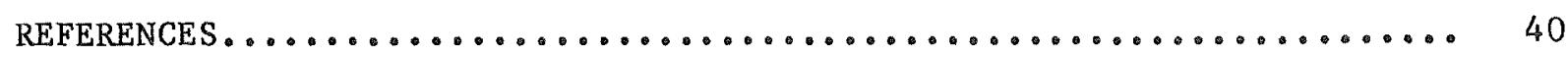

Professor, Chemical Engineering Department. 2 Professor, Mechanical Engineering Department. ${ }^{3}$ On leave from East China Institute of Chemical Technology, Shanghai, China. ${ }^{4}$ On leave from Institute of Chemical Metallurgy, Academia Scinica, Beijing, China. 


\section{INTRODUCTION}

Recently a new low-cost method has been investigated as a means of preparing very pure silicon from silane $\left(\mathrm{SiH}_{4}\right)$. The fundamental chemical reaction of this technology is

$$
\mathrm{SiH}_{4} \text { (gas) } \stackrel{\text { heat }}{\longrightarrow} \mathrm{Si} \downarrow+2 \mathrm{H}_{2} \text { (gas) . }
$$

When cold silane gas is heated, it decomposes forming solid silicon.

A number of methods of effecting this decomposition reaction are shown in Figures 1(a) and 1(b). Figure 1(a) is a free space reactor in which cold silane is injected into an externally heated reactor. With this system there are problems associated with the consolidation of the extremely fine dust which is formed, and with the formation of large agglomeration or scabs of solids which grow on the heating surfaces. Another way of preparing very pure silicon is to fluidize a bed of hot silicon particles with cold silane gas. Figure $1(b)$ is a normal externally heated fluidized bed with a silane feed. Because the silane will tend to condense out on the hottest surfaces, the problem with this system is to keep the bed particles hot while keeping the walls of the reactor cool. Figure $1(\mathrm{c})$ is an internally heated bed wherein the heater is located far above the inlet point at which the $\mathrm{SiH}_{4}$ is expected to decompose. Circulation of the fluid bed particles is designed to keep a sufficiently high temperature of particles near the inlet so as to obtain complete reaction at the bottom of the reactor.

The purpose of our research is to explore a still different processing method which uses radiant heating of the particles of a fluidized bed, as shown in Figure 1(d). The process involves heating the particles at the 


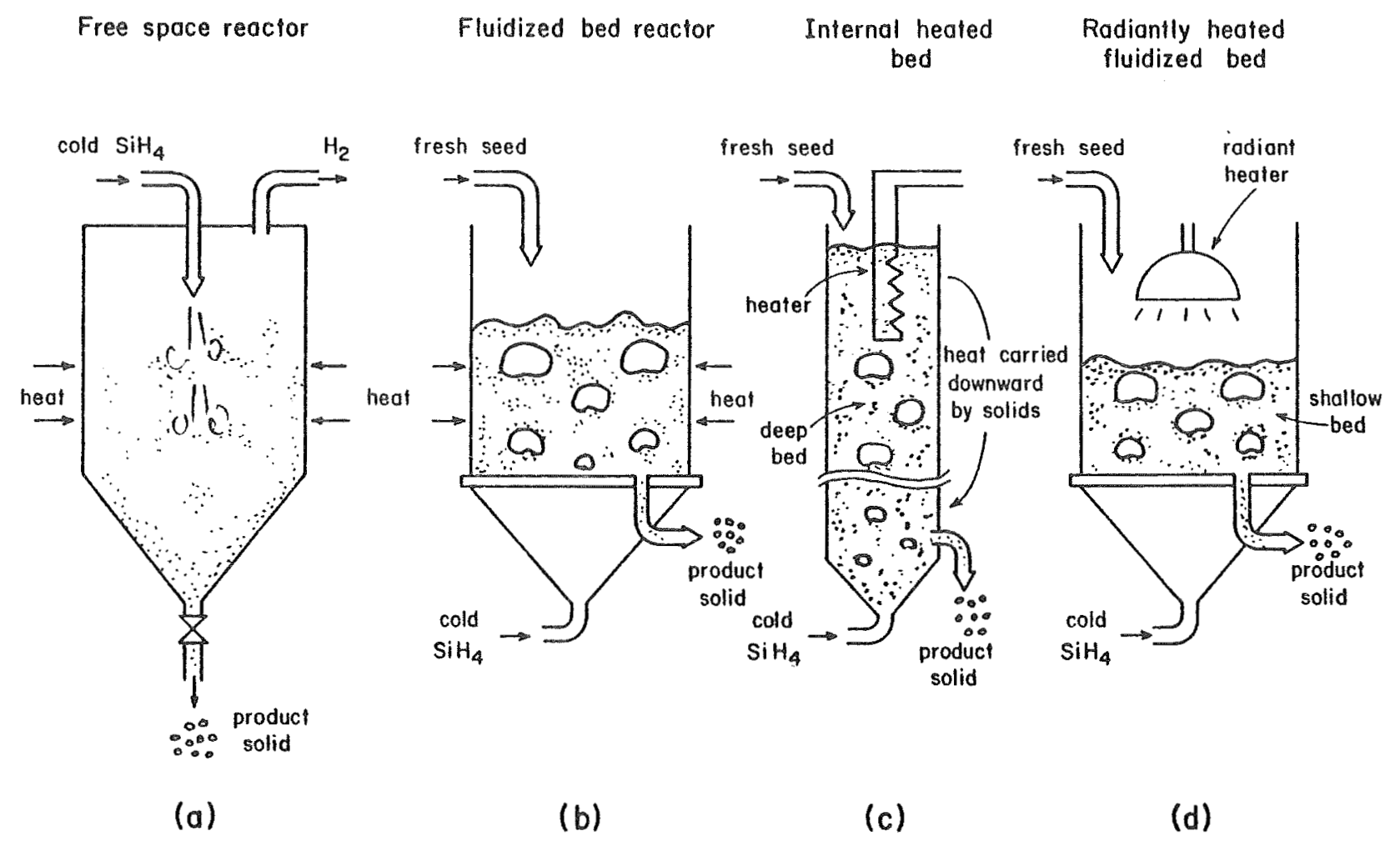

Fig. 1 Different ways to make very pure silicon from silane. 
surface of a shallow fluidized bed by radiant heaters located above the surface of the bed. The radiant sources could be cooled by a purge of inert gas which is exhausted with the spent $\mathrm{H}_{2}$. The hot bed particles would circulate down to the bottom of the bed where they would heat the cold silane gas rising through the distributor plate. Decomposition and deposition of the silane then follow.

Two important systems characteristics need to be evaluated. One is the effective absorptivity of the bed. This is the fraction of electrical energy supplied to the heaters which is actually absorbed by the particles. This involves the geometry and directionality of the heaters, the absorptivity of the surface of the fluid bed, and the flow of energy from the top to the bottom of the bed. This last named characteristic 1s primarily dependent on the circulation rate of the solids and the bed configuration, and is known to be very rapid.

The second important factor is the heat transfer coefficient between the hot bed and the cool distributor plate. Knowledge of this will allow prediction of the temperature of the distributor plate during silicon production. It is important that the distributor plate be kept below about $350^{\circ} \mathrm{C} \mathrm{[1];}$ otherwise silane will decompose while passing through it, depositing silicon, and plugging it. Thus knowledge of the heat transfer coefficient will determine what conditions (vessel geometry, feed gas temperature) will give satisfactory designs. 


\section{EXPERIMENTAL}

Apparatus and Materials

An outline of the experimental equipment is illustrated in Figure 2. Figure 2(a) shows that the bed may be considered to be composed of three parts. The upper expanding section is a square section tapered from $394 \mathrm{~mm}$ to $152 \mathrm{~mm}$ in a vertical distance of $440 \mathrm{~mm}$. The lower section is a square section tapered from $152 \mathrm{~mm}$ to $13 \mathrm{~mm}$ with a taper angle of $20^{\circ}$. The middle section is a square section with a $152 \mathrm{~mm}$ square distributor plate. Figure 2(b) is a square tapered bed with a $76 \mathrm{~mm}$ square distributor plate. Figure 2 (c) is a square tapered bed without distributor plate--we call this the square pyramid bed. Figure $2(d)$ is a normal $152 \mathrm{~mm}$ circular bed. It is made of $152 \mathrm{~mm}$ pyrex tubing with a $1000 \mathrm{~W}$ electric resistance heating coil just above the surface of the bed.

For the "cold" tests the heater used was a 1000 watt, 120 volt, spotlight (Sylvania Q1000PAR64NSP) mounted in a water-cooled copper shroud. For "hot" tests, four such lamps were mounted in a water-cooled heater assembly.

The distributor plate was made of a $1.6 \mathrm{~mm}$ thick sintered stainless steel plate with nominal $5 \mu \mathrm{m}$ pores obtained from Mott Metallurgical Corporation. Silicon particles for the fluidized bed were obtained from Union Carbide Corporation and were measured to have the following size distribution:

Mesh

\begin{tabular}{cccr} 
(U.S. Standard) & Opening $(\mu \mathrm{m})$ & $\mathrm{d}_{\text {screen, }}$ & $\mathrm{x}_{i}(W t \%)$ \\
\hline+40 & 425 & 425.0 & 0.02 \\
$-40+70$ & $425 / 212$ & 318.5 & 33.04 \\
$-70+80$ & $212 / 180$ & 196.0 & 27.35 \\
$-80+100$ & $180 / 150$ & 165.0 & 28.54 \\
$-100+140$ & $150 / 106$ & 128.0 & 10.24 \\
$-140+200$ & $106 / 75$ & 90.5 & 0.55 \\
-200 & 75 & 75.0 & 0.25 \\
\hline
\end{tabular}


Square bed
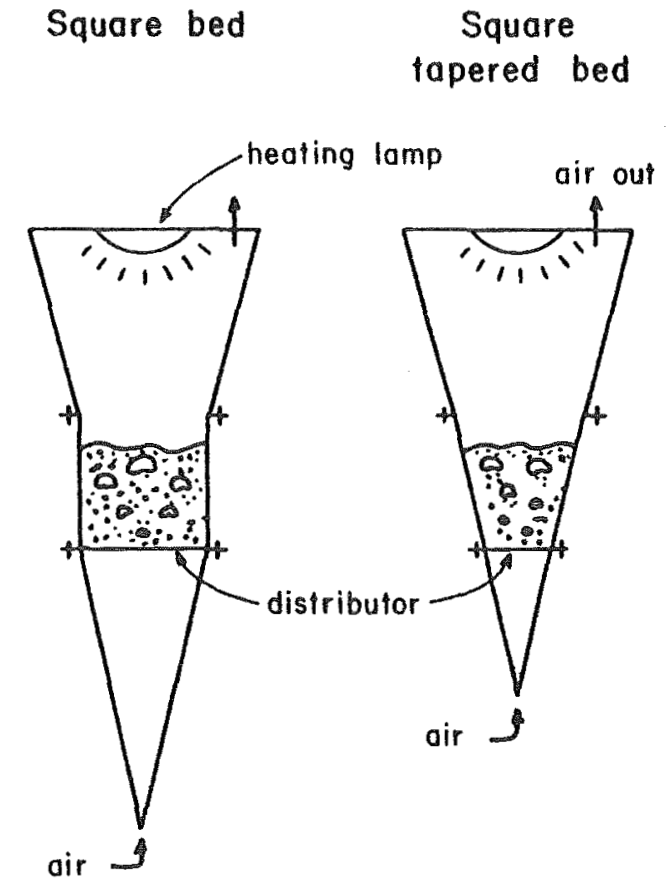

(a) (b)
Square pyramid bed

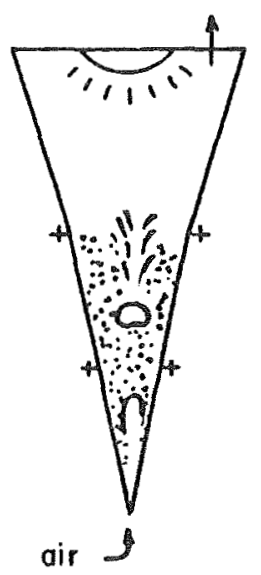

(c)

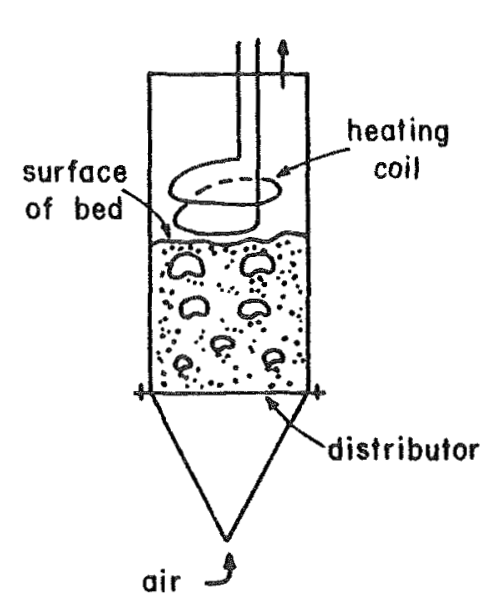

(d)

Fig. 2 Different geometries of the experimental beds used in this study, (a) $152 \mathrm{~mm}$ square bed with distributor plate,

(b) square tapered bed with $76 \mathrm{~mm}$ square distributor plate,

(c) square pyramid bed without distributor plate, and

(d) $152 \mathrm{~mm}$ round bed with heater directly above. 
The average screen diameter is Found to be

$$
\bar{d}_{\text {screen }}=\frac{1}{\left[\frac{x_{i} / 100}{\bar{d}_{\text {screen, }, i}}\right]}=198 \mu \mathrm{m}
$$

According to Levenspiel [2], for irregular particles with no seemingly longer or shorter dimension, the proper mean particle size to use for fluidization studies is

$$
\bar{d}_{p}=\frac{\phi+1}{2} \bar{d}_{\text {screen }}
$$

where $\phi$ is the sphericity which can be estimated from Kunii and Levenspiel [3] to be $\phi=0.63$. Thus the average particle diameter was estimated to be 161 $\mu \mathrm{m}$.

Properties of the silicon particles were therefore assumed to be as listed in Table 1.

Table 1. Properties of Silicon Particles.

\begin{tabular}{ll}
\hline Size distribution & $75 \sim 425 \mu \mathrm{m}$ \\
Mean size & $161 \mu \mathrm{m}$ \\
Density* & $2329 \mathrm{~kg} / \mathrm{m}^{3}$ \\
Bulk density & $1085 \mathrm{~kg} / \mathrm{m}^{3}$ \\
Heat capacity* & $711 \mathrm{~J} / \mathrm{kg} \cdot \mathrm{K}$ \\
Thermal conductivity* & $148 \mathrm{~W} / \mathrm{m} \cdot \mathrm{K}$ \\
Minimum fluidized velocity & $30 \mathrm{~mm} / \mathrm{s}$ \\
\hline
\end{tabular}

*at $25^{\circ} \mathrm{C}$, adapted from Yaws, et al [4]

Temperature measurements were made with chromel-alumel thermocouples of $0.254 \mathrm{~mm}$ diameter at locations specified in Figure 3 and were recorded using an Esterline Angus PD2064 data logger for steady-state tests. Transient tests 

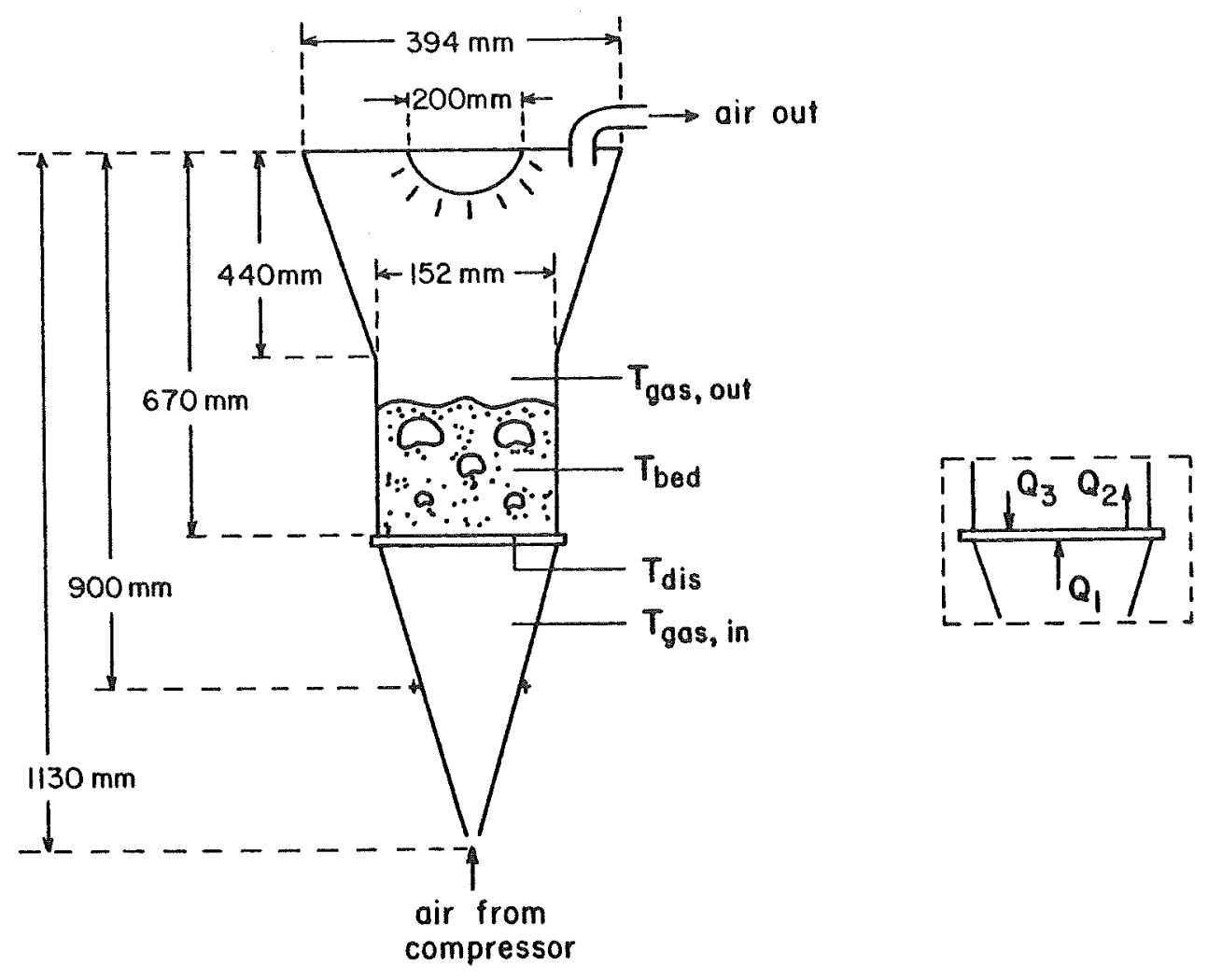

Fig. 3 Sketch of equipment (not to scale), location of temperature probes, and heat balance around the distributor plate. 
used $127 \mu m$ diameter chromel-alumel thermocouples with recording of data on a HP 3497 data logger.

Air discharged from the apparatus was routed through a low pressure drop air washer for capture of fines which may have elutriated from the bed.

\section{Procedure}

The experiments reported in this paper were designed to determine the effects of the variation of air velocity, bed height, and power level on the effective configurational absorptivity and the heat transfer coefficient from the bed to the distributor plate.

Two different experimental tests, steady state and transient (or pulsed) were used in the program. In the steady-state test, air at room temperature was passed upward through a bed of silicon particles at a known fixed rate to obtain a fluidized bed. The amount of energy input to a lamp above the bed was measured by a wattmeter. When the system came to thermal equilibrium, the inlet and outlet air temperatures, bed temperature, and distributor temperature were measured. In the transient (or pulsed) test the bed was allowed to reach steady state (initially near room temperature) and then a short duration pulse of radiant energy was provided to raise the bed temperature approximate1y $6^{\circ} \mathrm{C}$ above the steady-state value. The fraction of the electrical energy input in a pulse which was carried out by the air leaving the bed was defined as the effective absorptivity.

Since temperature measurements provided the basic data for determining the values of $h$, it was important to develop a means of measuring the temperature of the top surface of the distributor plate without disturbing the flow of particles, and without being influenced by the temperature of the particles. 
Figure 4 shows four different methods which were used to measure the top surface of the distributor plate. It was clear that the initial method, a, of fixing the thermocouple to the top of the distributor plate was not satisfactory. This thermocouple was much too responsive to the bed particle temperature. In methods $\mathrm{b}, \mathrm{c}$, and $\mathrm{d}$ thermocouples were brought through the distributor plate from below in order to eliminate the effect of the hot bed temperature. But in method $b$ the temperature measurement was still affected by the hot particles above the distributor. For method $c$ the temperature measuring point was not imbedded sufficiently in the distributor plate. Method $d$ was the method finally selected. The thermocouple wires were placed in a shallow groove in the top surface of the distributor plate and an epoxy cement was used to seal the gap around the wires.

It was observed that the distributor surface temperature fluctuated rapidly when air bubbles were present at the plate. As a consequence, a timeaveraging process using $8 \sim 10$ points was necessary to more accurately establish the mean surface temperature of the plate.

\section{THEORY}

Mechanism of Heat Transfer Between Distributor Surface and Fluidized Bed

Experimentally obtained heat transfer coefficients between bed walls or exchanger surfaces and fluidized beds have been explained in terms of various mechanisms by different authors as follows:

(1) Steady-state conduction of heat across the gas film, which is scoured by solids descending along the heat exchange surface: Leva et al $[5,6]$, Dow and Jakob [7], Levenspiel and Walton [8]. 


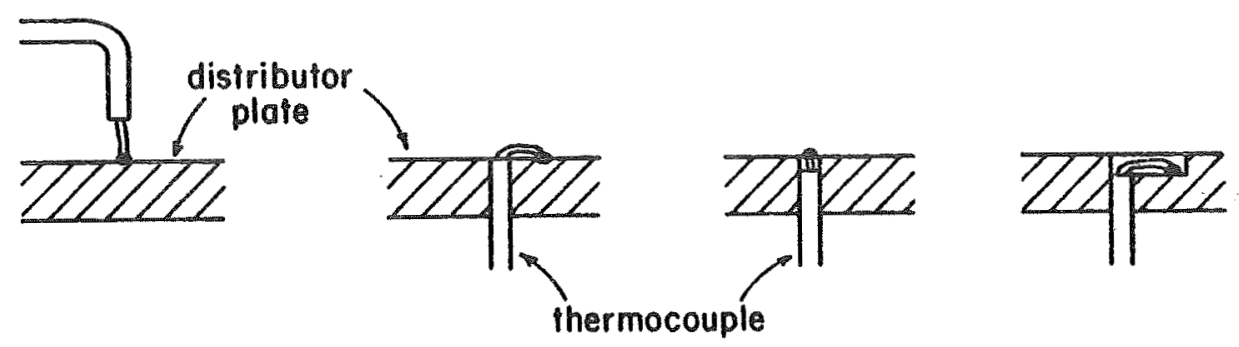

Fig. 4 Different method of measure the temperature of the surface of the distributor plate. 
(2) Unsteady-state thermal conduction by single particles in direct contact with heat exchange surface: Botterill and Willians [9], and Ziegler et al [10].

(3) Unsteady-state absorption of heat by fresh emulsion elements which are renewed intermittently by the violent disturbances in the core portion of the fluidized bed: Mickley et al $[11,12]$.

(4) Steady-state conduction through the emulsion layer which is not often swept away. van Heerden et al [13,14] and Wicke and Fetting [15].

It would be useful to develop criteria to suggest which mechanism controls and which type of model should be used to represent a particular situation. Following the film-penetration theory for mass transfer, originally developed by Toor and Marche11o [16], Yoshida et al [17] proposed a mechanism of heat transfer between a fluidized bed and wall surface which included both steady-state conduction of heat through an emulsion layer at the wall and the unsteady-state absorption of heat by emulsion elements.

The mechanism of heat transfer between the distributor plate and a fluidized bed has not been discussed previously in the literature. It should be pointed out that here the direction of heat transfer is opposite to the direction of the air flow, rather than normal to it, as is the case in most heat exchangers. In comparing these mechanisms we see that these are two contrasting situations, as shown in Figure 5. In the first case there exists a film of gas at the heat transfer surface, while in the second this film is absent, and heat is transferred to the distributor plate primarily by impingement of hot bed particles on the surface. 


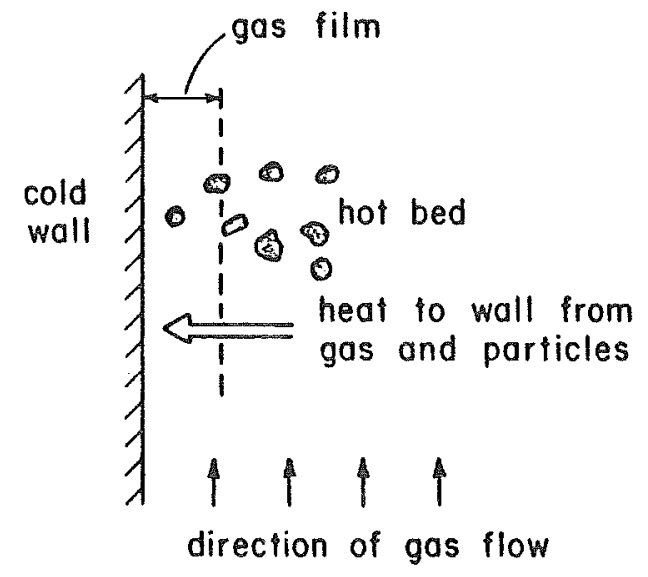

(a)

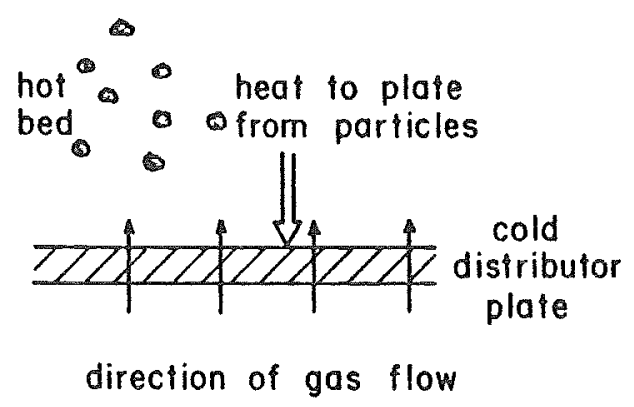

(b)

Fig. 5 (a) In heat transfer to bed walls or to bed internals a gas film is present at the surface.

(b) In heat transfer to a distributor plate no gas film is present. 
Even though the film is absent we may represent the heat transfer rate by a heat transfer coefficient which depends on the bed geometry, gas and particle properties, and fluidization characteristics which in turn affect the collision frequency of particles with distributor plate.

Calculation of the Effective Heat Transfer Coefficient Between the Bed and the Distributor Plate, h

The heat transfer coefficient is defined so that at steady-state the thermal energy added to the air in passing through the distributor plate is equal to the energy transferred from the bed to the distributor plate by the action of the bed particles. Referring to Figure 3, at steady state we have, in symbols

$$
\mathrm{Q}_{2}-\mathrm{Q}_{1}=\mathrm{Q}_{3}
$$

or

$$
\dot{\mathrm{m}}_{\text {air }} \mathrm{C}_{\mathrm{p}, \text { air }}\left(\mathrm{T}_{\text {air,leaving }}-\mathrm{T}_{\text {air,entering }}\right)=\mathrm{hA}_{\text {dis }}\left(\mathrm{T}_{\text {bed }}-\mathrm{T}_{\mathrm{dis}}\right)
$$

If the air leaving the distributor is assumed to be at the temperature of the top of the distributor plate then

$$
h=\frac{\dot{\mathrm{m}}_{\text {air }} \mathrm{C}_{\mathrm{p}, \text { air }}\left(\mathrm{T}_{\mathrm{dis}}-\mathrm{T}_{\text {air,in }}\right)}{\mathrm{A}_{\mathrm{dis}}\left(\mathrm{T}_{\text {bed }}-\mathrm{T}_{\text {dis }}\right)}
$$

Measuring the bed, distributor, and inlet air temperature then allows calculation of $h$.

Calculation of the Effective Absorptivity of the Bed

A certain fraction $f_{1}$ of the electrical energy provided to the lamps is transformed into radiant energy; and then a certain fraction $f_{2}$ of this 
radiant energy is actually absorbed by the bed itself. The fraction $f_{1}$ is a characteristic of the radiation source (the lamps used), while the fraction $\mathrm{f}_{2}$ depends on the system geometry and the absorptivity of the bed surface. The product $f_{1} \cdot f_{2}$ is called the effective absorptivity $\alpha$ of the system.

So if $\mathrm{P}$ is the power input to the lamps then

$$
\mathrm{f}_{1} \mathrm{f}_{2} \mathrm{P}=\alpha \mathrm{P}=\mathrm{Q}_{1 \text { amp to bed }}=Q_{\text {to heat air }}
$$

or

$$
\alpha \mathrm{P}=\dot{\mathrm{m}}_{\text {air }} \mathrm{C}_{\mathrm{p}, \text { air }}\left(\mathrm{T}_{\text {bed }}-\mathrm{T}_{\text {air,in }}\right)
$$

The factors $f_{1}$ and $f_{2}$, in particular $f_{2}$, are the quantities which are required; however only their product $\alpha$ is found directly by experiment.

\section{RESULTS AND DISCUSSION}

$\Delta \mathrm{p}$ vs. $\mathrm{u}_{\mathrm{o}}$ for Three Different Bed Geometries

Figure 6 shows the pressure drop curve for the $152 \mathrm{~mm}$ square bed. It is similar to that of an ordinary fluidized bed.

Figure 7 shows the pressure drop-air flow characteristics for a tapered square bed with a $76 \mathrm{~mm}$ square distributor plate for three different settled bed heights. The velocity quoted in this figure is the superficial velocity based on the area of the distributor plate. It was observed that at low flow rates the air simply passed up through the settled solids without disturbing the particles. With further increase in the air flow, the surface of the bed suddenly erupted and there was a sudden drop in pressure. The maximum pressure drop observed is called the pressure peak. Beyond this pressure peak the bed bubbled and spouted, with pressure drop close to the theoretical. The 


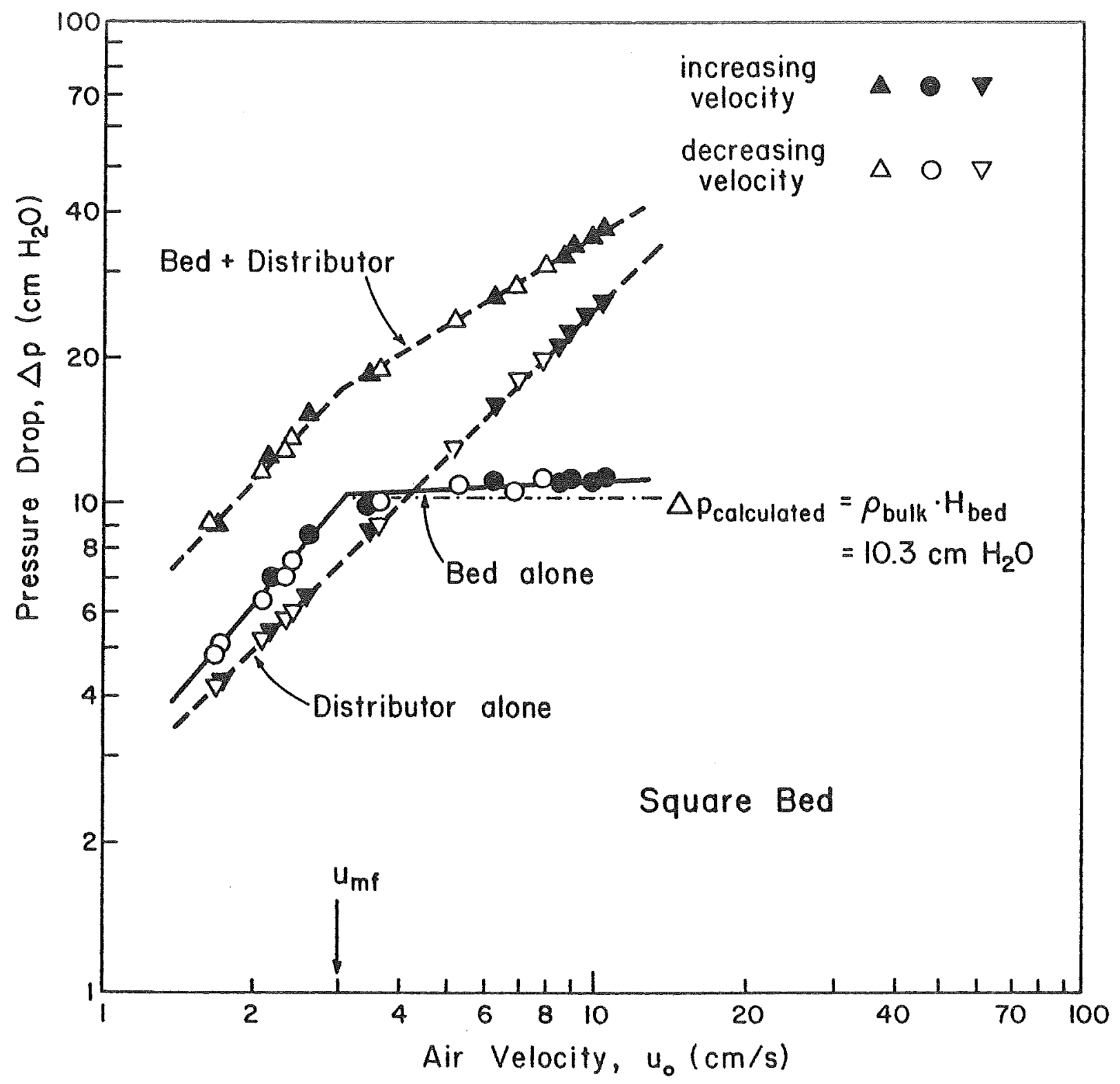

Fig. 6 Pressure drop curves for a square bed, $\mathrm{H}_{\text {bed }}=9.5 \mathrm{~cm}$. 


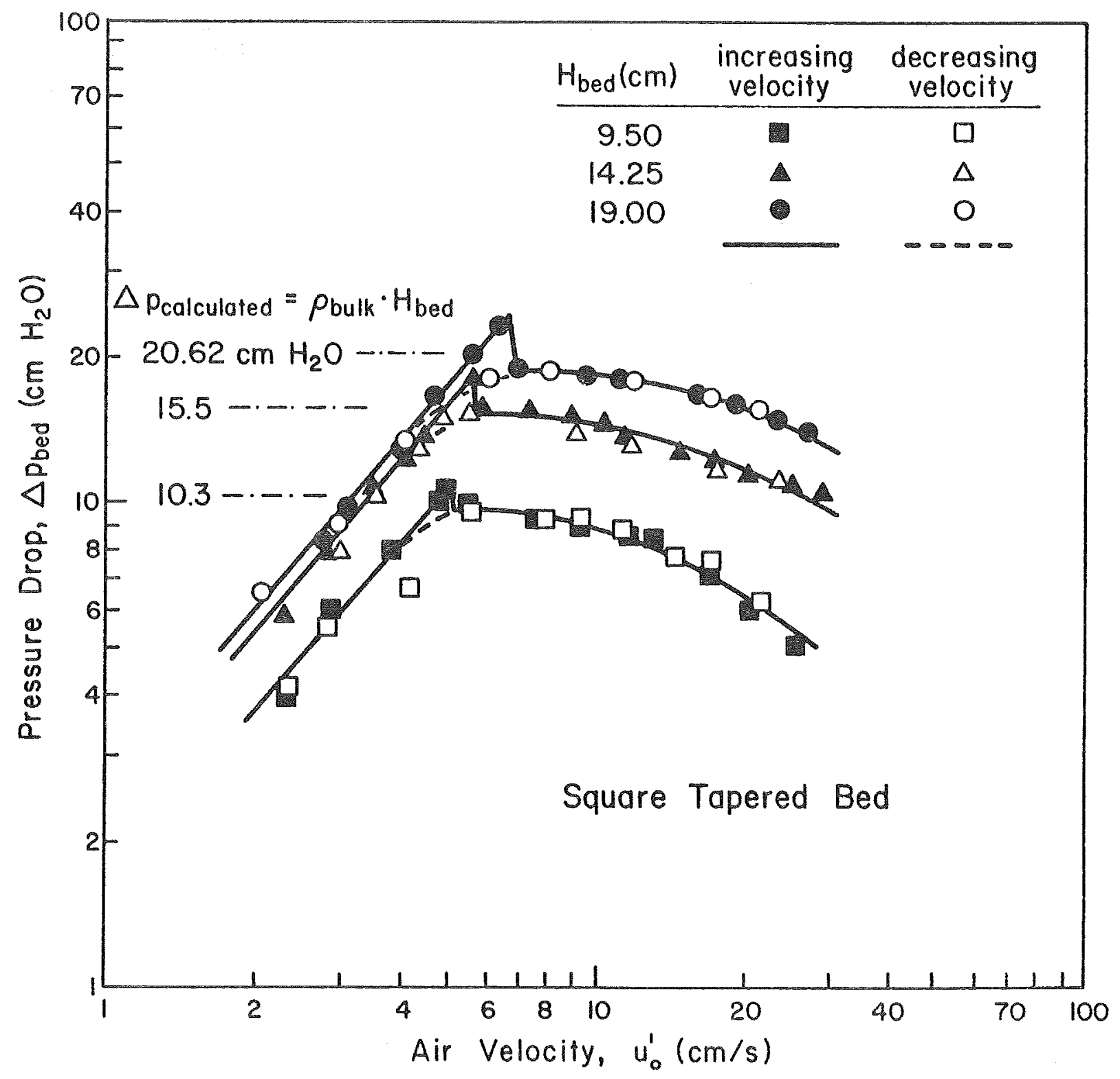

Fig. 7 Pressure drop curves for a square tapered fluidized bed, distributor subtracted, for three different settled bed heights . 
pressure drop decreased progressively with further increase in velocity. No pressure peak was observed when the velocity was decreased.

Figure 8 is a plot of pressure drop versus air velocity for a tapered square bed without distributor, or the pyramid bed, for three different settled bed heights. It was observed that because the gas velocity was large at the bottom of the bed, the particles at the bottom of the bed started fluidizing while those in the upper portion of the bed remained static. With a further increase in the flow rate of gas, layer after layer of solids became fluidized with the upper portion still remaining in a fixed bed state. The bed pressure drop thus increased continuously until the entire bed was spouted. Just before this stage was reached there was a sharp reduction in pressure drop to the theoretical. With a further increase in air velocity, the pressure drop decreased slightly and then increased slightly. This in crease may be attributed to the energy loss by collision and friction among particles as well as between particles and the walls of the container. The energy loss was larger in the tapered bed than in a normal fluidized bed because the movement of the particles is quite different in these different geometries. This progression of events is consistent with other observations in tapered beds $[18,19]$.

Both Figures 7 and 8 show that there is a minimum spouting velocity at a certain bed depth which becomes large as the bed height increases.

Effect of Power Level on $\alpha$

Figure 9 shows, in the range of $300-800 \mathrm{~W}$, that the effective absorptivity is independent of the power level used in the one-lamp runs. The value of $\alpha$ would be expected to change only if the lamp efficiency changed significantly with power level. This did not happen. 


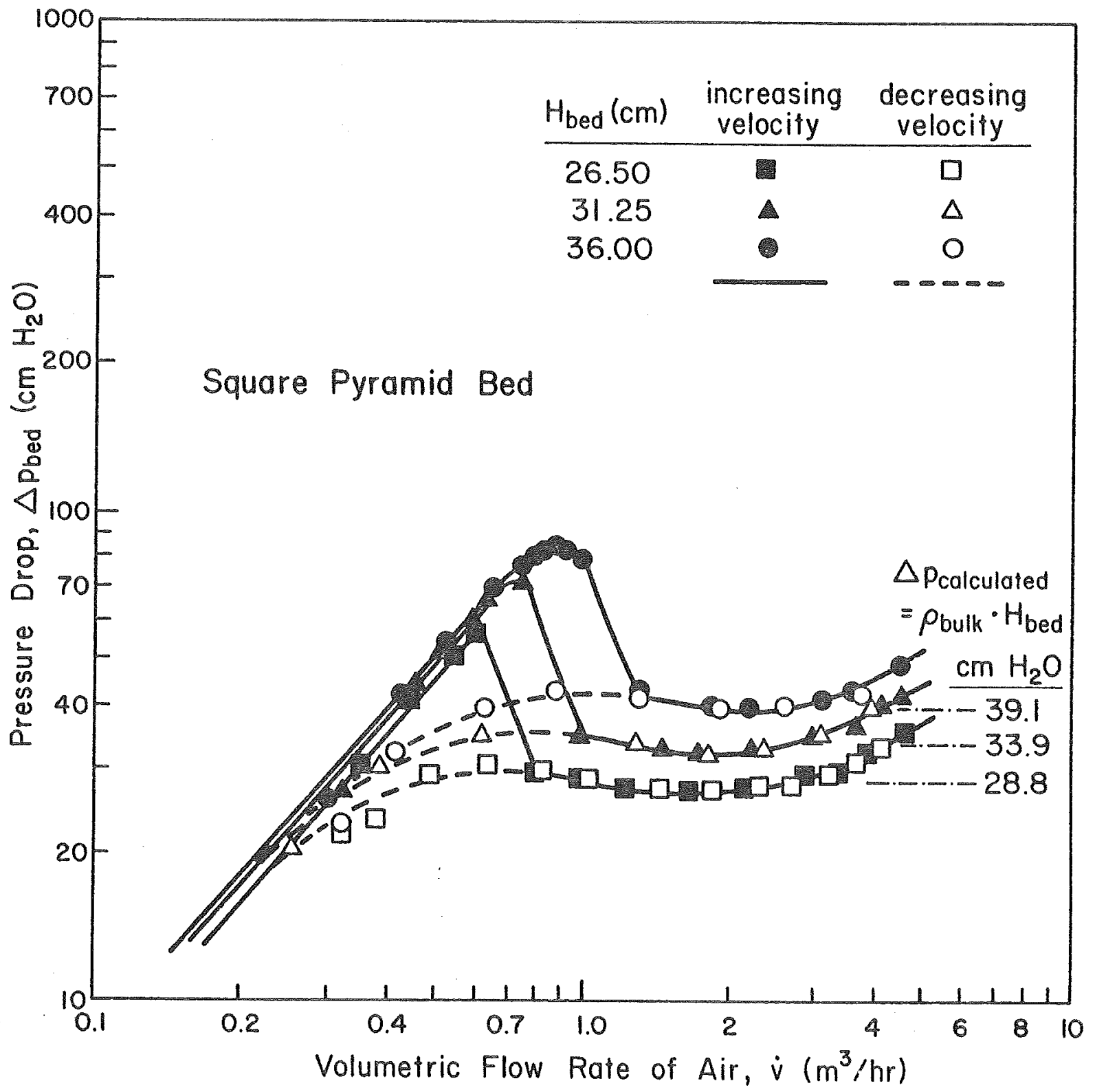

Fig. 8 Pressure drop curves for a square pyramid bed having no distributor, for three different settled bed heights. 


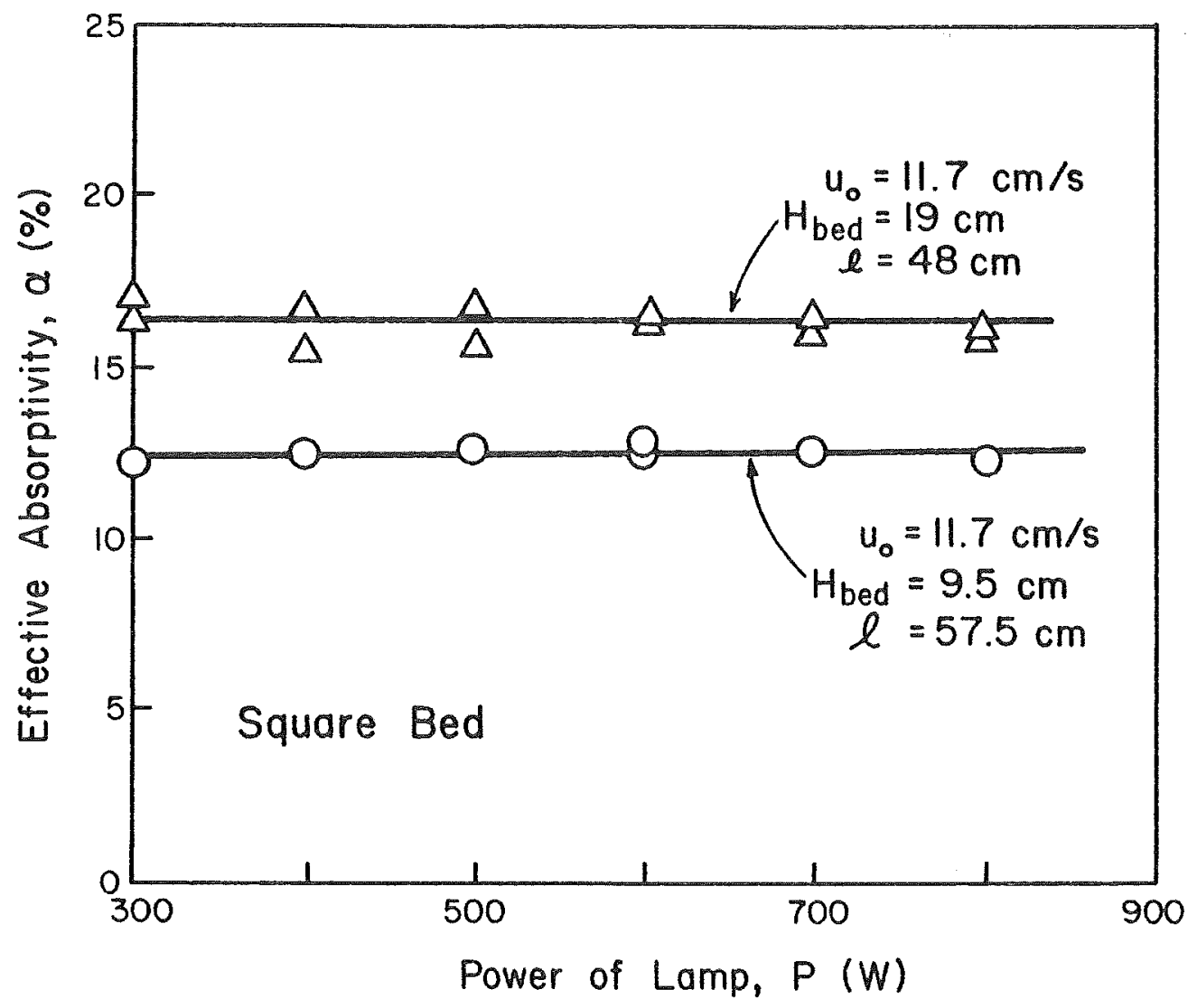

Fig. 9 Effective absorptivity is independent of power level but is affected by bed height, hence distance from lamp to bed surface. 
Figure 9 also shows that $\alpha$ does change with bed height, hence with distance between lamp and bed surface. The reason is that the configuration factor is a strong function of the distance between lamp and bed surface.

Effect of Power Level and Temperature Level on $\mathrm{h}$

Figure 10 shows clearly that the heat transfer coefficient in experiments with the resistance element located just above the bed surface and in both one-1amp and four-1amp experiments is independent of bed temperature for all bed geometries tested.

This finding shows that the heat transfer coefficient $h$ is a legitimate vartable for representing the rate of heat transfer from bed to distributor plate.

As a result of the above findings on power level of the lamps, the power level was kept at $600 \mathrm{~W}$ for the remainder of the one-1amp runs.

Effect of Air Velocity and Bed Depth on h

Figures 11, 12, and 13 show the results of experiments which examine these variables in beds of different geometries.

First of all it is clearly seen, in all three bed geometries, that bed depth does not affect $h$.

Regarding air velocity and $h$ it is seen that in the round bed (Figure 11) $\mathrm{h}$ rises to a maximum at about $2 \mathrm{u}_{\mathrm{mf}}$, then decreases slowly with increase in gas velocity.

On the other hand, in the square bed (Figure 12) h rises progressively and quite sharply with an increase in gas velocity. This is probably caused by the exaggerated circulation of particles in a bed of this geometry, with particles rising in the center of the bed, and sliding downward in the four 


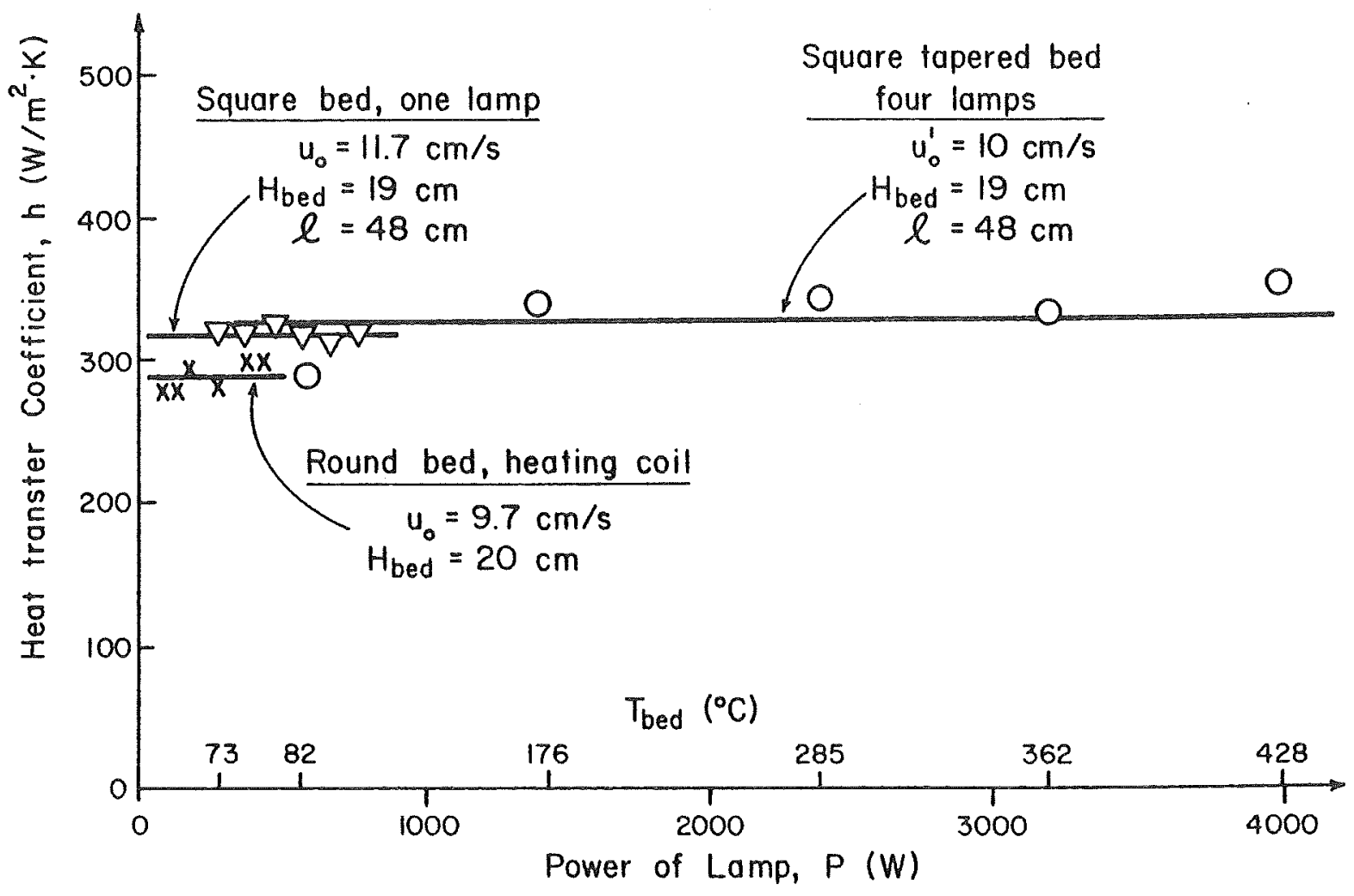

Fig. 10 Heat transfer coefficient is independent of bed temperature and lamp power. 


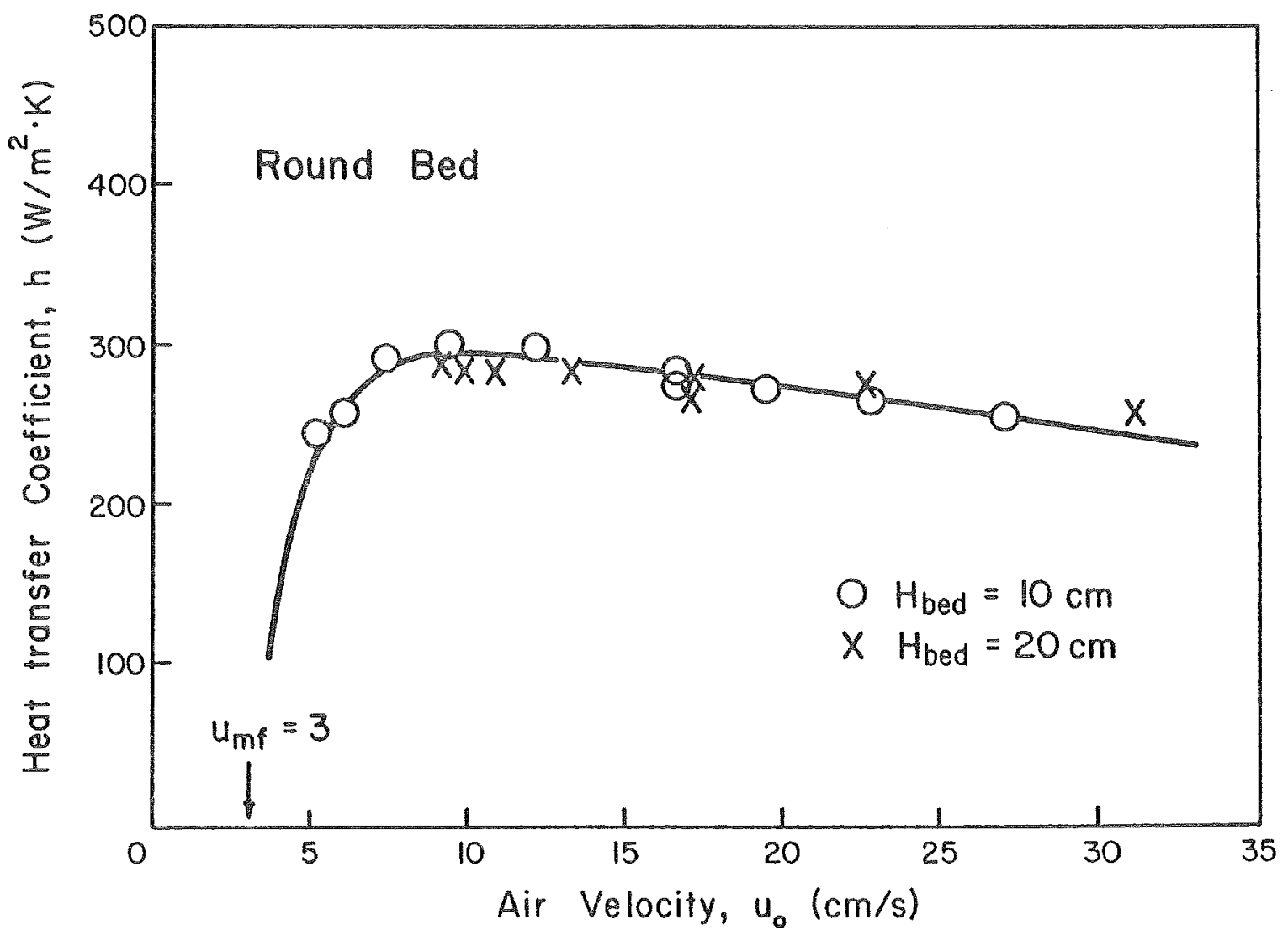

Fig. 11 Variation of heat transfer coefficient with air velocity for a round bed; power level of the coil heater, $P=160 \mathrm{~W}$. 


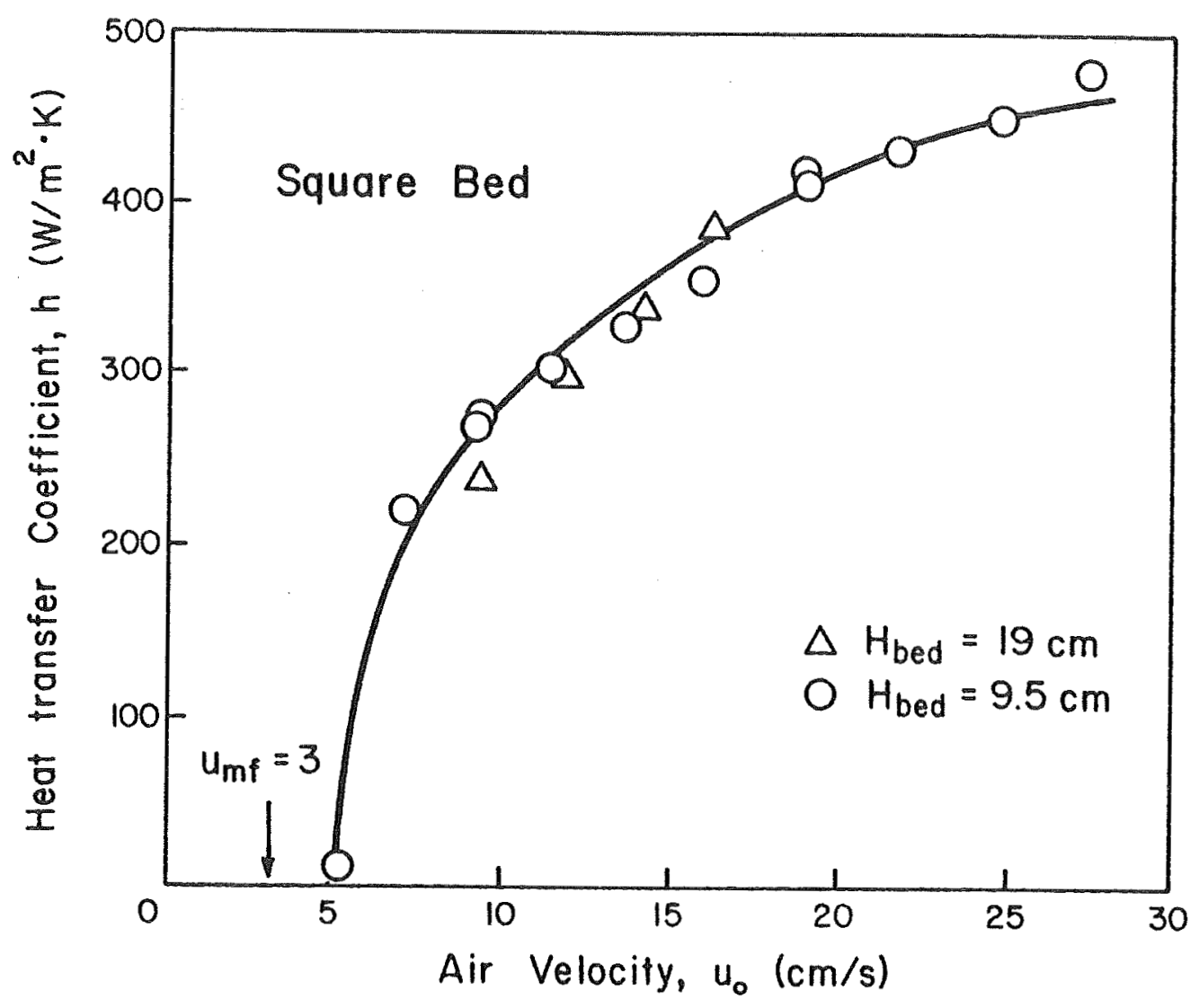

Fig. 12 Variation of heat transfer coefficient with air velocity for a square bed; lamp power, $\mathrm{P}=600 \mathrm{~W}$. 


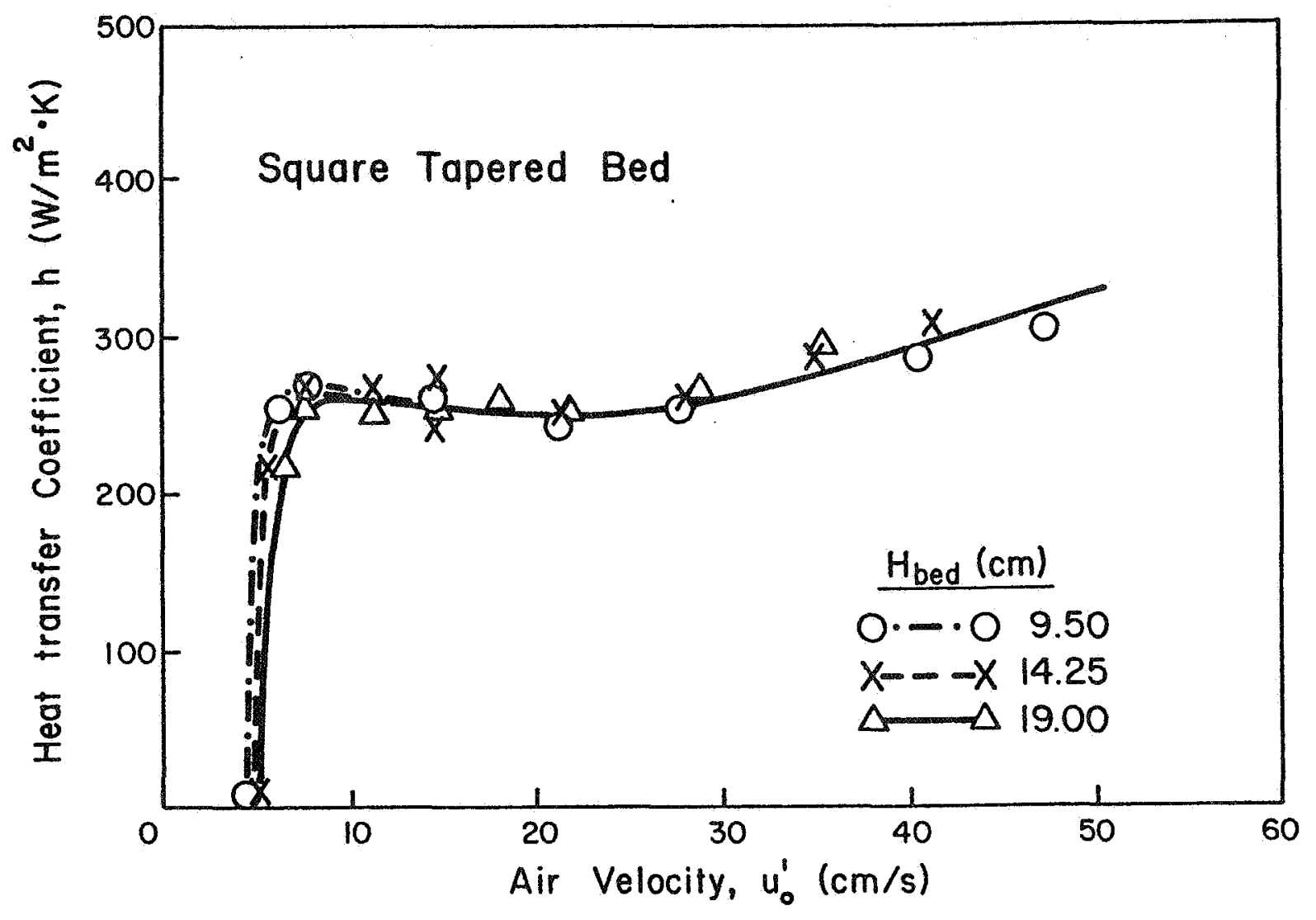

Fig. 13 Variation of heat transfer coefficient with air velocity for a square tapered bed; lamp power, $\mathrm{P}=600 \mathrm{~W}$. 
corners of the bed. This movement enhances the flow of fresh particles across the distributor plate, giving a higher $h$. An increase in air velocity will amplify this action causing $h$ to increase progressively with air velocity. In the square tapered bed (Figure 13) $\mathrm{h}$ reaches a maximum at a velocity slightly greater than $u_{m f}$, drops slightly, and then gradually increases with a further increase in $u_{0}$. This behavior looks to be somewhere between that of the round and the square bed. At low air velocity in the tapered bed solid circulation is not severe, hence the round bed behavior dominates; however at high air velocity the square bed behavior with its severe solid circulation caused by the corners dominates.

\section{Effect of Air Velocity on $\alpha$}

Figures 14 16 show the effects of air velocity on $\alpha$ for three different bed configurations. These curves clearly indicate that $\alpha$ increases as the velocity increases. This is the result of a higher average surface level of the bed (and therefore a larger configuration factor between the heated source and the bed), more effective absorption due to the more irregular bed surface and the particles thrown up close to the $1 \mathrm{amp}$.

It is observed that those geometries which cause more violent disturbances of the bed surface result in greater rates of change of $\alpha$. In terms of the configurations shown in Figures $2(a),(b)$, and (c); type (c) has the greatest effect upon the value of $\alpha$ as air flow is increased while type (a) has the least effect.

Effective Absorptivity - Experiment

Figure 17 displays the measured $\alpha$ values in three different kinds of beds, and is a crossplot of Figures 14, 15 and 16. 


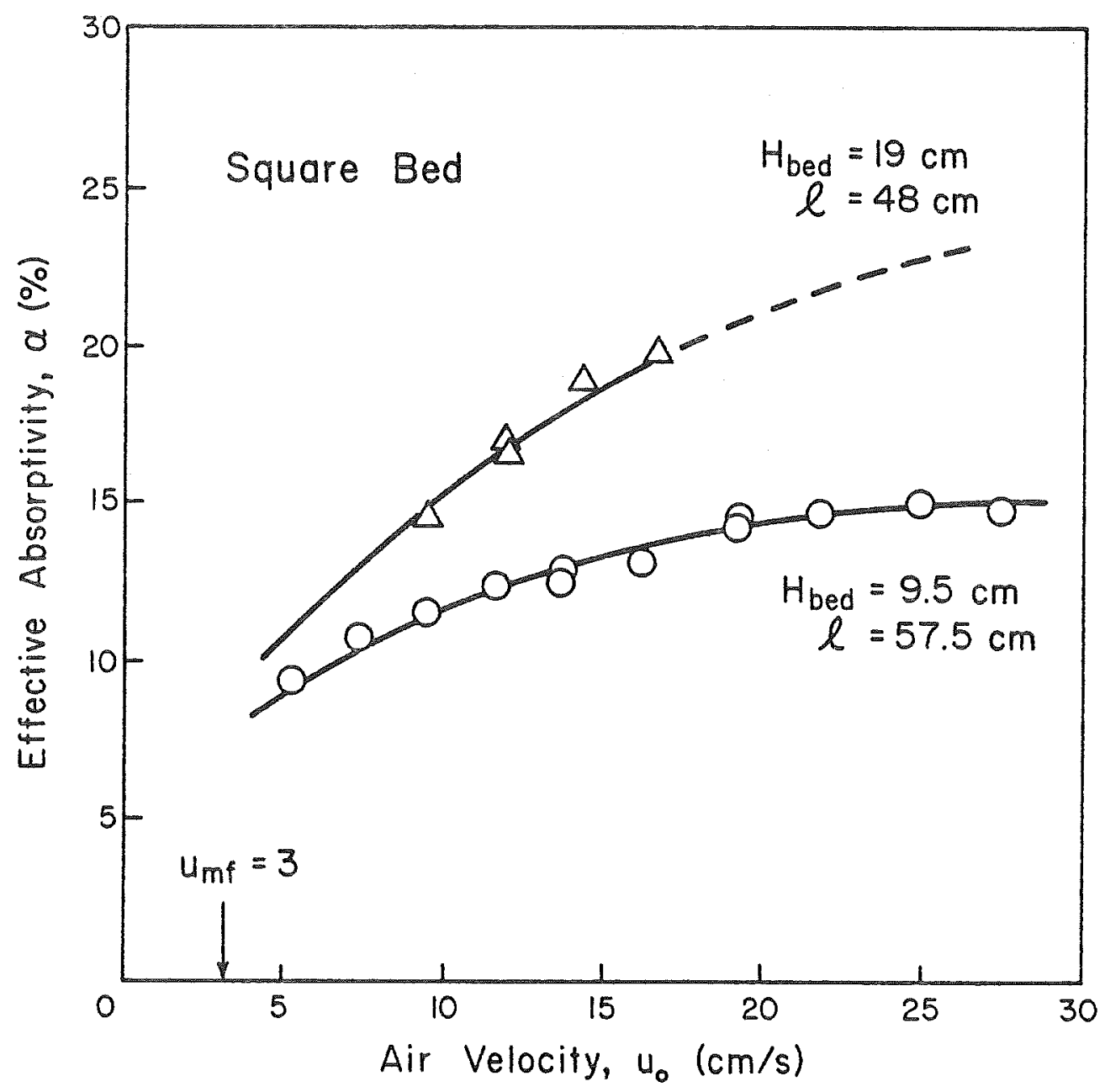

Fig. 14 Effects of air velocity on $\alpha$ for two different settled bed heights of square bed; lamp power, $\mathrm{P}=600 \mathrm{~W}$. 


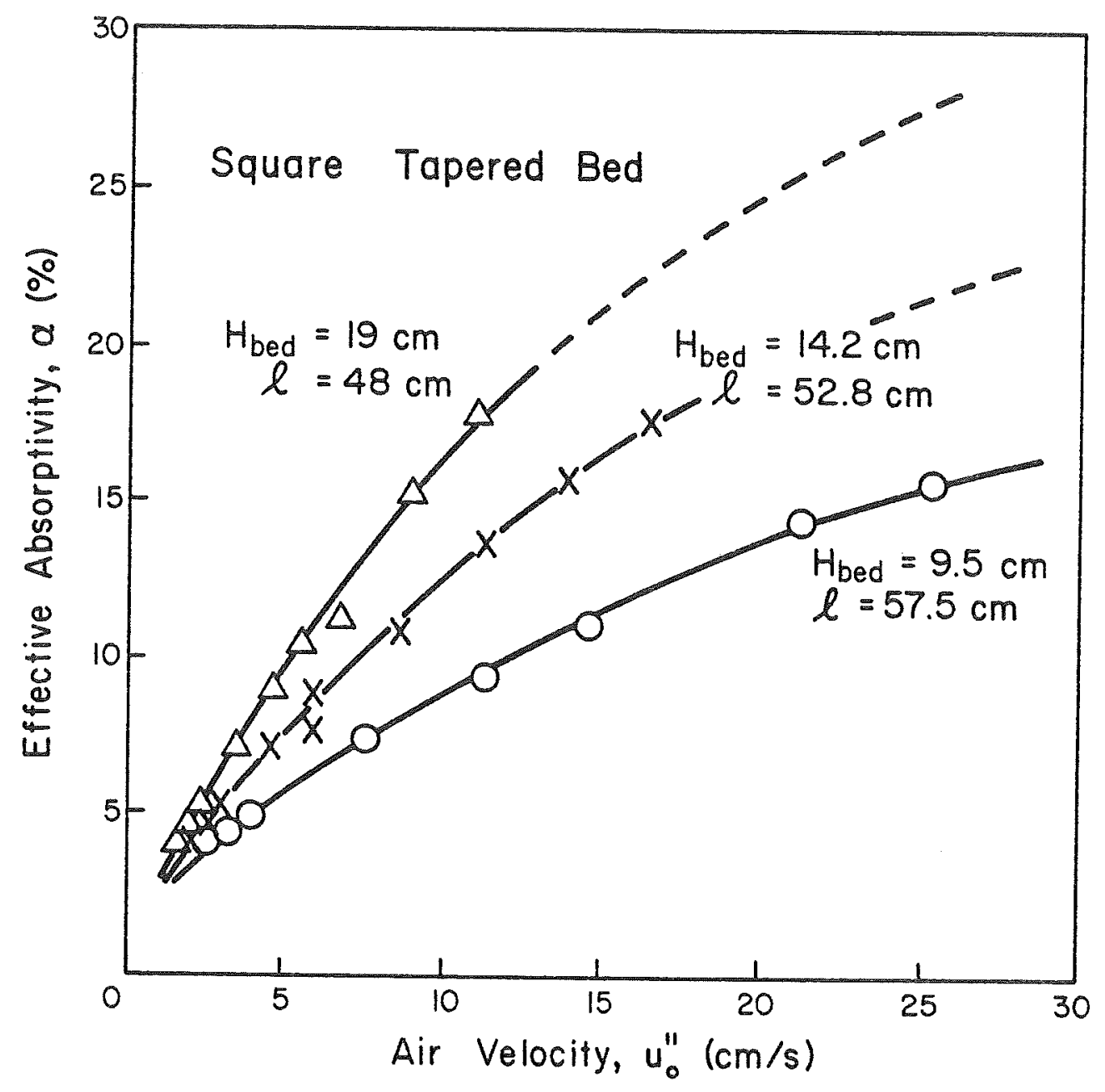

Fig. 15 Effects of air velocity on $\alpha$ for three different settled bed heights in a square tapered bed; lamp power, $P=600 \mathrm{~W}$. 


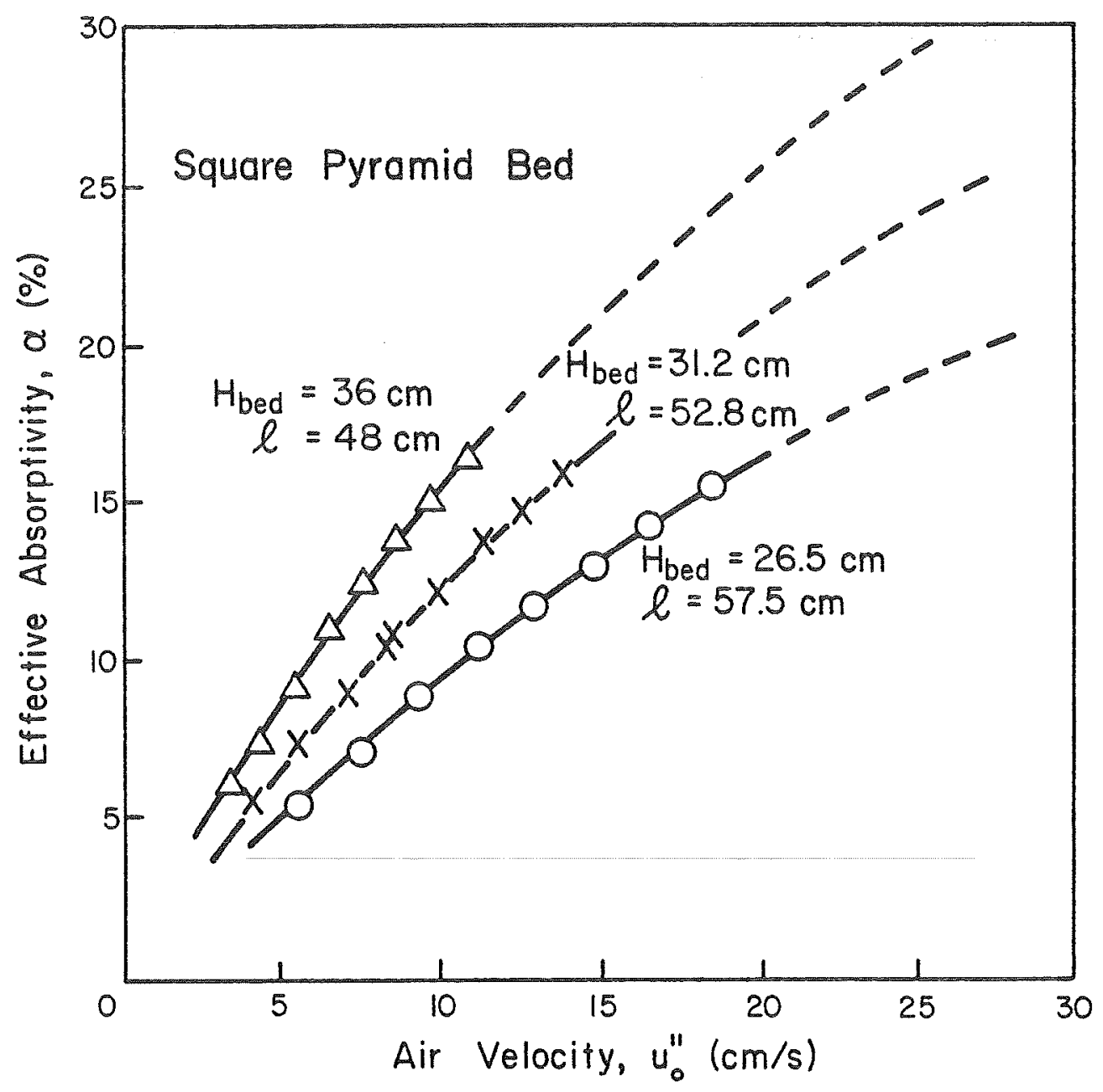

Fig. 16 Effects of air velocity on $\alpha$ for three different settled bed heights in a square pyramid bed; lamp power, $\mathrm{P}=600 \mathrm{~W}$. 


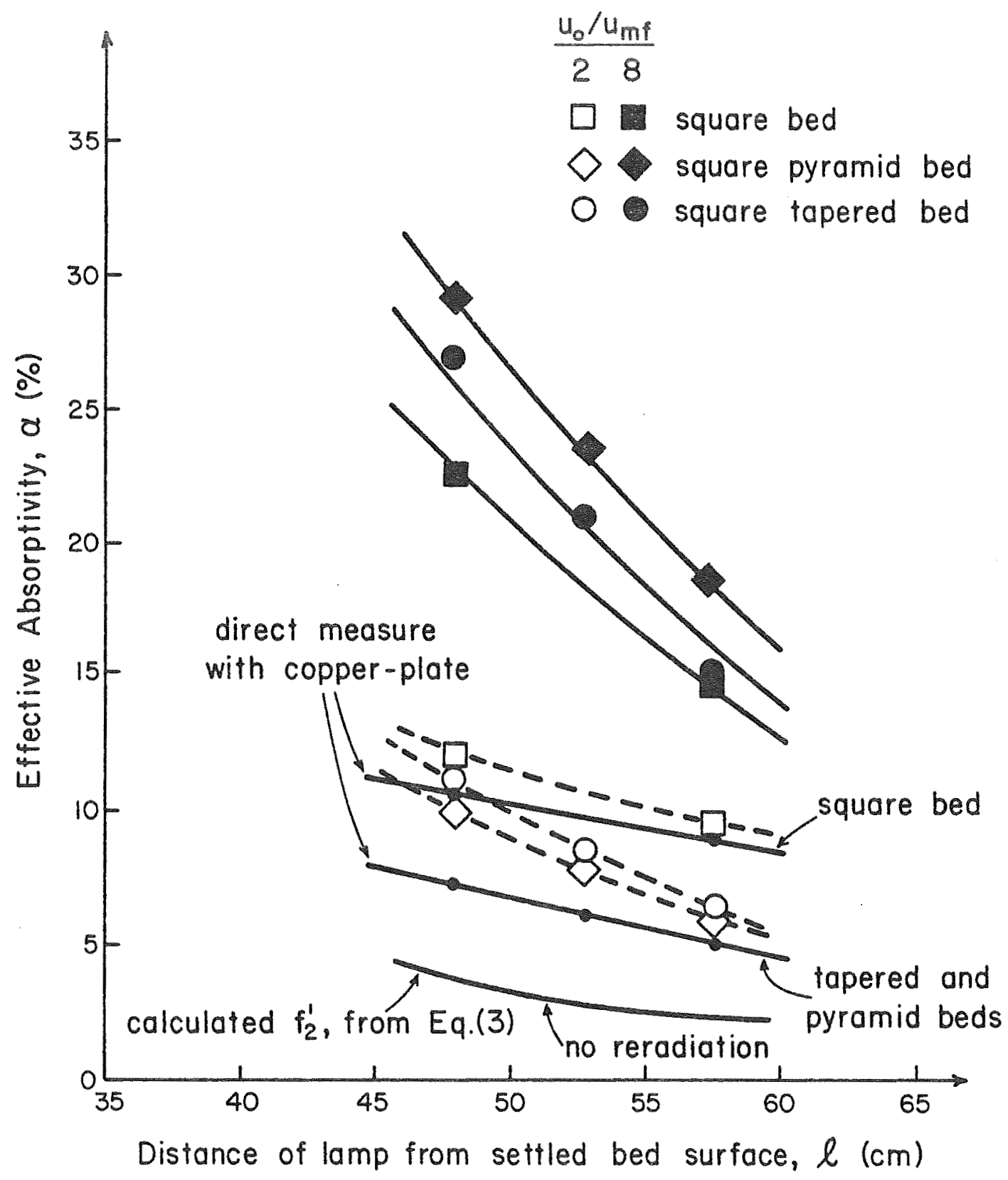

Fig. $17 \alpha$ varies with distance of lamp from settled bed surface; experimental values compared to the calculated values and to direct measurements. 
Two observations stand out clearly: first, that bringing the lamps closer to the bed surface increases $\alpha$, at both high and low gas velocity. This result is expected. Secondly, higher gas velocities give higher $\alpha$ values. This finding can be a result of two factors.

(a) Bed expansion at higher gas velocity brings the bed surface closer to the lamp.

(b) The severe bubbling action at higher gas velocity results in a more irregular surface, in which particles are thrown into the freeboard, much closer to the radiation source.

We also note that at low velocity the tapered and pyramid beds have a lower $\alpha$ than the square bed. This is because their top surfaces are in tapered regions, and their upper cross-sectional areas are smaller than that for the square bed. Increasing $\ell$ amplifies this effect.

\section{Effective Absorptivity - Prediction}

Prediction of the effective absorptivity is difficult because the geometrical effect considered in the conventional configuration factor assumes that radiation occurs from a diffusely radiating source. Because a major attempt was made to obtain a directional source rather than a diffuse one, this type of modeling is bound to be in error. However, the diffuse model should represent the lower limit for the actual situation. For direct radiation between diffuse source and sink Siegel and Howell [20] give

$$
f_{2}^{\prime}=\frac{1}{2}\left\lfloor 2+s^{2}-\sqrt{s^{4}+4 s^{2}}\right\rfloor \text {, where } s=\ell / r
$$


In the real situation the transfer of energy should be greater than that given by Eq. (3). Figure 17 shows that this is so.

Effective Absorptivity - Direct Measurement

A series of transient tests were performed in which a pulse of radiant energy was directed onto a blackened copper plate (absorptivity = 1) placed at the surface of the settled bed. From the rate of rise of the plate temperature it was possible to get a direct measurement of the effective absorptivity in this bed geometry. The measured value is also shown in Figure 17.

Note, that at close to $u_{m f}$ the copper plate and the bed measurements are close to each other. However, at higher gas velocity where the bed expands (decrease in $\ell$ ) and has an irregular surface, with particles ejected into freeboard, the bed measurements give a larger $\alpha$, as expected.

SUMMARY OF EXPERIMENTAL FINDINGS AND THEIR RELEVANCE IN SCALE-UP

1. Lamp power. In all runs the effective absorptivity of the bed $\alpha$ and the heat transfer coefficient at the distributor plate $h$ are independent of the lamp power used.

2. Bed depth does not affect h. However, since bed depth changes the distance between the bed surface and the lamp it affects the view factor, hence $\alpha$.

3. Bed geometry, gas velocity and $\alpha$. The value of $\alpha$ is strongly dependent on the distance between radiation source and bed surface--smal1 distance, large $\alpha$. Also, $\alpha$ increases sharply with increase in gas velocity. Roughly, from Figure 17, we have for $\alpha$ : 


\begin{tabular}{lcc} 
& $u_{0} / u_{\mathrm{mf}}=2$ & $u_{0} / u_{\mathrm{mf}}=8$ \\
\hline$\ell=48 \mathrm{~cm}$ & $11 \%$ & $26 \%$ \\
$\ell=57.5 \mathrm{~cm}$ & $7.5 \%$ & $16 \%$ \\
\hline
\end{tabular}

At high velocities tapered beds have higher $\alpha$ than nontapered beds, most likely because tapered beds experience more violent bubbling, more irregular bed surfaces, and more particles thrown into the freeboard where they are closer to the radiation source. 4. Bed geometry, gas velocity and $h$. For all geometries tested the data show that at gas velocities a bit above $u_{m f}\left(\sim 2 u_{m f}\right)$ the $h$ values were all roughly about $\mathrm{h}=260 \sim 300 \mathrm{~W} / \mathrm{m}^{2} \cdot \mathrm{K}$. With an increase in velocity beyond this point

- $h$ decreased slowly and progressively in round beds (see Figure 11).

- h continued to rise sharply and continuously in square beds (see Figure 12).

- $h$ decreased a bit, then increased slowly in tapered beds (see Figure 13)

Thus at many multiples of $u_{\mathrm{mf}}(>4)$ we would expect generally that

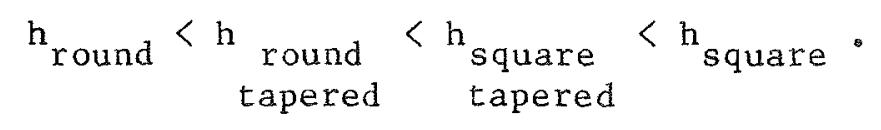

Conical and square pyramid beds have no distributor plates hence $h$ is not pertinent to such systems. 
CALCULATIONS FOR SCALE-UP

The two conditions to be satisfied in operating the scaled-up reactor are that

- the bed temperature is to be kept at about $700^{\circ} \mathrm{C}$ (good dense deposit of silicon on the particles at this temperature).

- the distributor plate should not be hotter than about $350^{\circ} \mathrm{C}$ otherwise silane will decompose while passing through the distributor plate and plug it.

\section{Base Case Calculation}

Let us start with a $152 \mathrm{~mm}$ square bed, filled to a height of $19 \mathrm{~cm}(\ell=$ $48 \mathrm{~cm}$ ) with particles of the size used in this study $\left(\overline{\mathrm{d}}_{\mathrm{p}}=161 \mu \mathrm{m}\right)$, and fluidized with room temperature gas at a velocity of $u_{0}=120 \mathrm{~mm} / \mathrm{s}$ (or $u_{0}=4$ $\left.u_{\mathrm{mf}}\right)$. Let us determine the power level $\mathrm{P}$ and heat transfer coefficient needed to meet the above requirements of this process.

1. Power input level. The required power level is found from Eq. (2), or

$$
\alpha \mathrm{P}=\dot{\mathrm{m}}_{\text {gas }} \mathrm{C}_{\mathrm{p} \text {,gas }}\left(\mathrm{T}_{\text {bed }}-\mathrm{T}_{\text {gas, in }}\right)
$$

where

$$
\begin{array}{ll}
\alpha & \cong 0.14, \text { from Figure } 17 \\
\dot{\mathrm{m}}_{\text {gas }} & =\mathrm{u}_{0} \mathrm{~A}_{\mathrm{dis}} \rho_{\text {gas }}=(0.120)(0.152)^{2}(1.2)=0.0033 \mathrm{~kg} / \mathrm{s} \\
\mathrm{C}_{\text {p,gas }} & =1004 \mathrm{~J} / \mathrm{kg} \cdot{ }^{\circ} \mathrm{C} \\
\mathrm{T}_{\text {bed }} & =700^{\circ} \mathrm{C} \\
\mathrm{T}_{\text {gas, in }} & =20^{\circ} \mathrm{C}
\end{array}
$$

Substituting all values into Eq. (2) gives

$$
0.14 P=(0.0033)(1004)(700-20)
$$


from which the power level needed is

$$
P=16 \mathrm{~kW}
$$

2. Required h. This is found from Eq. (1), or

$$
h=\frac{\dot{m}_{\text {gas }} C_{\text {p,gas }}\left(T_{\text {dis }}-T_{\text {gas,in }}\right)}{A_{\text {dis }}\left(T_{\text {bed }}-T_{\text {dis }}\right)}
$$

where

$$
\begin{aligned}
& \mathrm{T}_{\text {dis }}=350^{\circ} \mathrm{C} \\
& \mathrm{T}_{\text {gas, in }}=20^{\circ} \mathrm{C}
\end{aligned}
$$

and the other values are tabulated above.

Replacing all values gives

$$
\mathrm{h}=\frac{(0.0033)(1004)(350-20)}{(0.152)^{2}(700-350)}=135 \mathrm{~W} / \mathrm{m}^{2} \cdot \mathrm{K}
$$

Operation of the Base Case Bed

Here we see that we need a very large power input, $16 \mathrm{~kW}$, to get the bed up to $700^{\circ} \mathrm{C}$. At higher gas flow rates the power input should increase a small amount, not proportionately (note that a rises sharply).

$$
\text { Since } h_{\text {needed }}=135 \mathrm{~W} / \mathrm{m}^{2} \cdot \mathrm{K} \text { while } \mathrm{h}_{\text {measured }}=250 \sim 300 \mathrm{~W} / \mathrm{m}^{2} \cdot \mathrm{K} \text { we cannot }
$$
keep the distributor cool enough with a square or round bed. Thus we must go to either a tapered bed with

$$
\frac{A_{\text {dis }}}{A_{\text {surface }}}<\frac{135}{300}=0.45
$$

or a conical bed with no distributor, or to a multiorifice or multicone bed. 
Scale-Up to a $450 \mathrm{~mm}$ Round Bed, $u_{0}=8 u_{\mathrm{mf}}$ and $\ell=48 \mathrm{~cm}$

Energy flux - The shape of the bed should not affect the energy flux to the bed, however the bed cross section and the lamp-to-bed distance should. From Eq. (3) the view factors for this bed size are calculated to be

\begin{tabular}{cc} 
Round bed, $d_{b}$ & View factor, $f_{2}^{\prime}$ \\
\hline $152 \mathrm{~mm}$ & 0.024 \\
$450 \mathrm{~mm}$ & 0.156 \\
\hline
\end{tabular}

As a crude estimate let us say that $\alpha$ goes from 0.14 to 0.25 . Thus the power consumption of the larger bed will be

$$
(16 \mathrm{~kW})\left(\frac{450}{152}\right)^{2} \frac{0.14}{0.25}=79 \mathrm{~kW}
$$

Distributor plate. The heat transfer coefficient should not change much with scale-up, hence the same consideration

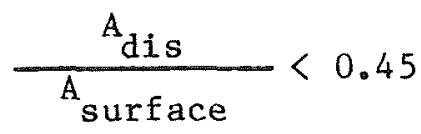

should apply to the big and the small bed.

Increasing the gas velocity. At higher gas velocities particles are thrown closer to the lamps thus $\alpha$ is higher. But the energy flux needed is proportional to the mass flow rate of air. The net effect of these two opposing effects is to require a higher energy flux to the bed, but a lower energy input per unit of throughput (or silicon produced).

\section{Significance for Design and Final Comments}

The above calculations suggest

1. The lamp-to-bed distance should be kept as small as possible. 
2. The efficiency of utilization of radiant energy improves with scale-up.

3. The ordinary vertical sided fluidized bed resting on a distributor plate is not a practical design.

4. The multicone or multiorifice bed is an attractive design for larger beds.

5. Having heat flux onto the upper bed surface, rather than through the bed walls, and maintaining a relatively shallow bed should not lead to especial difficulties in scale-up.

6. As a possible design of this type consider the sketch below: Note that at the lower portion of the bed the cross sectional area increases drastica11y. This just happens to be the zone of rapid gas expansion due to reaction and due to the sharp temperature rise.

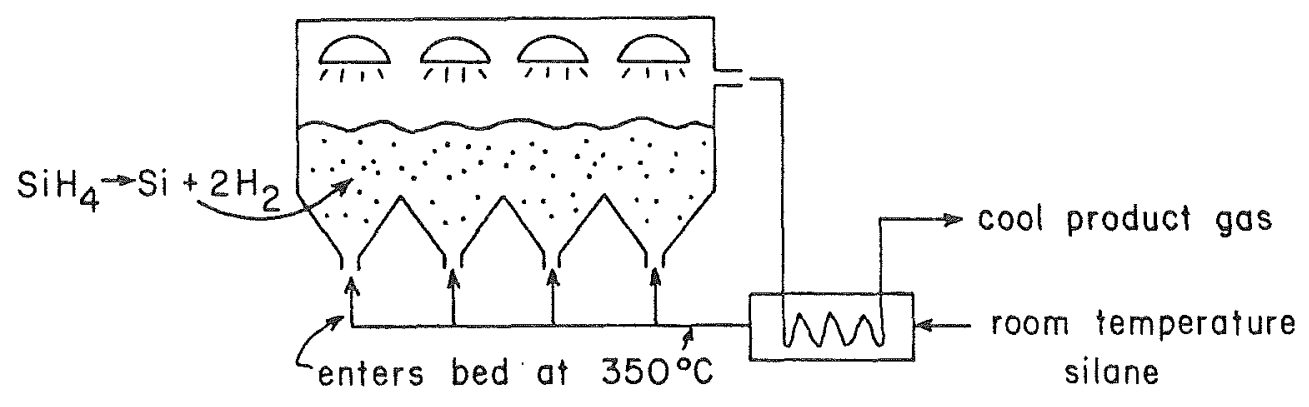

Taking the effective absorptivity at $\alpha \cong 0.25$ the power requirement should be roughly (ignore the small heat of reaction and assume that silane and air have the same properties)

$$
\begin{aligned}
P=\dot{\mathrm{m}}_{\text {gas }} & \mathrm{C}_{\mathrm{p} \text {,gas }}\left(\mathrm{T}_{\text {gas, out }}-\mathrm{T}_{\text {gas, in }}\right) / 0.25 \\
& =\left(0.0033 \frac{\mathrm{kg}}{\mathrm{s}}\right)\left(1004 \frac{\mathrm{J}}{\mathrm{kg} \cdot \mathrm{C}}\right)\left(700^{\circ} \mathrm{C}-350^{\circ} \mathrm{C}\right) \frac{1}{0.25} \\
& =4.6 \mathrm{~kW} \ldots \text { for the } 152 \mathrm{~mm} \text { bed }
\end{aligned}
$$

Energy flux $=4.6 \mathrm{~kW} /(0.152 \mathrm{~m})^{2}=200 \mathrm{~kW} / \mathrm{m}^{2}$ of bed surface 
Energy Requirement $=4.6 \mathrm{~kW} /\left(0.0033 \frac{\mathrm{kg} \mathrm{feed} \mathrm{gas}}{\mathrm{s}}\right)$

For a feed of pure silane this translates into

$$
1400 \mathrm{~kJ} / \mathrm{kg} \mathrm{Si} \text { produced }=0.4 \mathrm{~kW} \cdot \mathrm{hr} / \mathrm{kg} \mathrm{Si}
$$

and for a feed of $y \%$ silane the energy requirement is approximately

$$
1400 /\left(\frac{\mathrm{y}}{100}\right) \mathrm{kJ} / \mathrm{kg} \mathrm{Si} \text { produced }=40 / \mathrm{y} \mathrm{kw} \cdot \mathrm{hr} / \mathrm{kg} \mathrm{Si}
$$

These calculations are only a crude order of magnitude approxination. At this stage there is little need to be more precise.

7. Only two, nonreactive aspects of this process have been looked at in this preliminary research project. Other aspects of this process, such as

- proper size distribution to use

- stabilization of the size distribution in steady state operations

- proper feeding and removal of product solids

- quality of the silicon deposit in beds of different geometry

- materials of construction for the reactive bed

- selection of the proper radiation source,

these should all be examined and the problems overcome, before this approach to the production of silicon can begin to look practical.

\section{ACKNOWLEDGEMENT}

This study is sponsored by Jet Propulsion Laboratory, California Institute of Technology under Contract No.956133, Task Order No. RD-152/66. We would also like to point out that the concept being studied--the shallow, radiant heated fluidized silane-to-silicon reactor--is the brainchild of Dr. Thomas J. Fitzgerald, patent applied for by JPL. 


\section{LIST OF SYMBOLS}

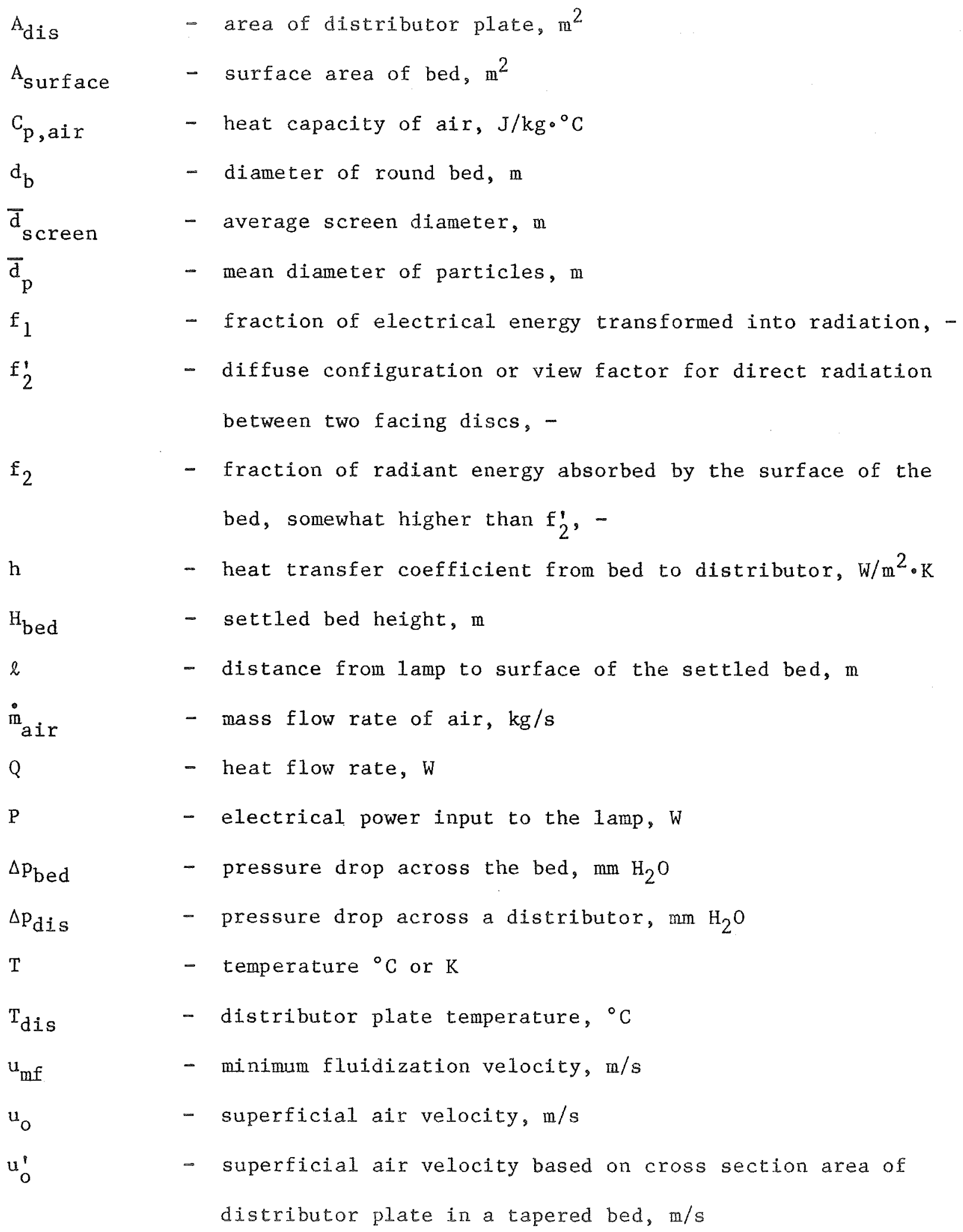




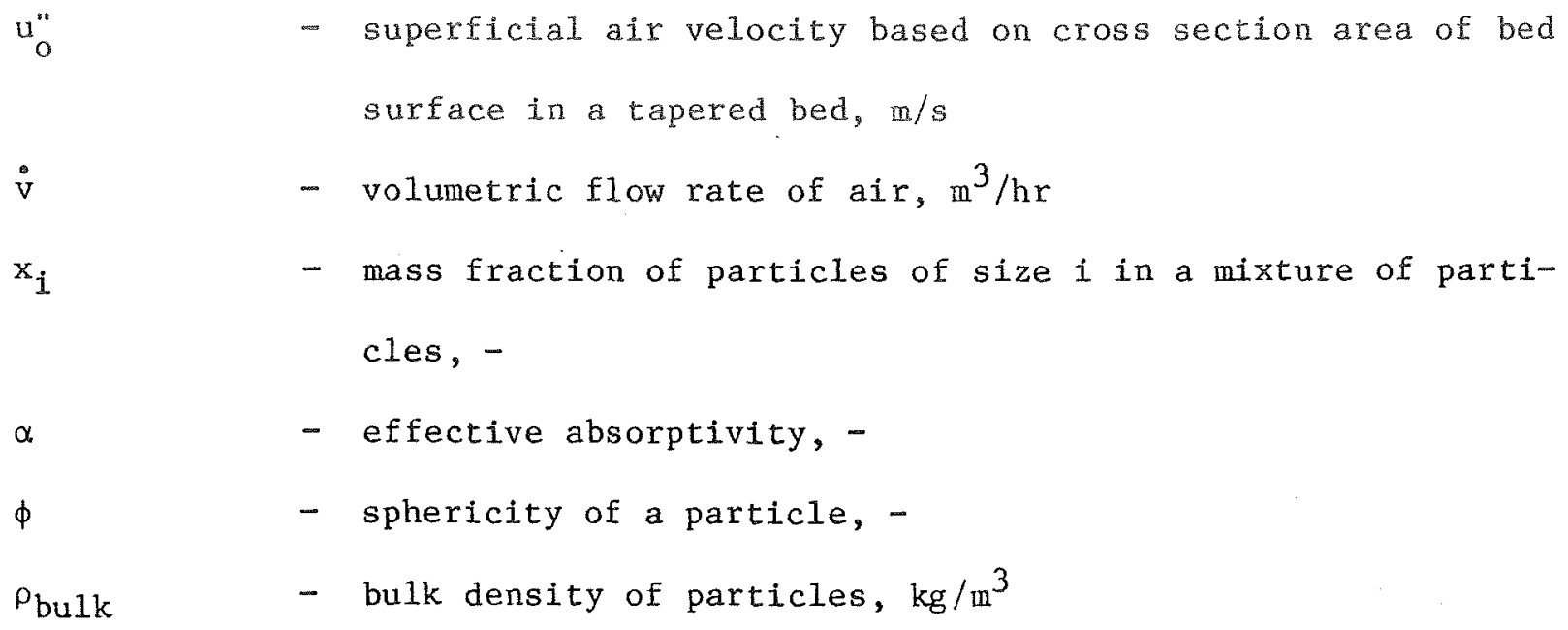




\section{REFERENCES}

1. N.K. Rohatgi, G.C. Hsu, and R. Lutwack, "Silane pyrolysis in a fluidized bed reactor," Jet Propulsion Laboratory, California Institute of Technology, internal report.

2. 0. Levenspiel, Fluid Flow and Heat Exchange, Chapter 6, Plenum, in press, 1983.

3. D. Kunii and 0 . Levenspiel, Fluidization Engineering, p. 65, Krieger, 1977.

4. C.L. Yaws, L.L. Dickens, R. Lutwack and G.C. Hsu, "Semiconductor industry silicon: physical and thermodynamic properties," Solid State Technology, p. 87, Jan. 1981.

5. M. Leva, M. Weintraub and M. Grummer, "Heat transmission through fluidized beds of fine particles," Chem. Engrng. Prog., 45, 563-572, (1949)。

6. M. Leva and M. Grummer, "A correlation of solids turnover in fluidized systems," Chem. Engrng. Prog., 48, 307-312, (1952).

7. W.M. Dow and M. Jakob, "Heat transfer between a vertical tube and a fluidized air-solid mixture," Chem. Engrng. Prog., 47, 437-648, (1951).

8. 0. Levenspiel and J.S. Walton, "Bed-wall heat transfer in fluidized systems," Chem. Engrng. Prog. Symp.Ser., 50(9), 1-13, (1954).

9. J.S.M. Botterill and J.R. Williams, "The mechanism of heat transfer to gas fluidized beds," Trans. Instn. Chem. Engrs., 41, 217-230, (1963).

10. E.N. Ziegler, L.B. Koppel, and W.T. Brazelton, "Effects of solid thermal properties on heat transfer to gas fluidized beds," I/EC Fundamentals, 3 , $324-328,(1964)$. 
11. H.S. Mickley, D.F. Fairbanks and R.D. Hawthorn, "The relation between the transfer coefficient and themal fluctuations in fluidized bed heat transfer," Chem. Engrng. Prog. Symp.Ser., 57 (32), 51-60, (1961).

12. H.S. Mickley and D.F. Fairbanks, Mechanism of heat transfer to fluidized beds," AIChE Journa1, $1,374-384$, (1955).

13. C. van Heerden, P. Nobel and D.W. van Krevelen, "Studies on fluidization - II. Heat Transfer," Chem. Engrng. Sci., 1, 51-66, (1951).

14. C. van Heerden, P. Nobel and D.W. van Krevelen, "Mechanism of heat transfer in fluidized beds," Ind. Engrng. Chem., 45, 1237-1242, (1953).

15. E. Wicke and F. Fetting, Wämeubertragung in gaswirbelschichten," ChemieIngr-Tech., 26, 301-309, (1954).

16. H.L. Toor and J.M. Marchello, "Film penetration model for mass and heat transfer," AIChE Journa1, 4, 97-101, (1958).

17. K. Yoshida, D. Kunii and 0 . Levenspiel, "Heat transfer mechanisms between wall surface and fluidized bed, Int. J. Heat Transfer, 12, 529-536, (1969).

18. A. Kumar, Y. Chandra and N. Gopal Krishna, "Studies on fluidization in tapered vesse1s," Indian Chemical Engineer, 23(3), 8-13, (1981).

19. K.B. Mathur and N. Epstein, Spouted Beds, P. 14-17, Academic Press, 1974. 20. R. Siegel and J.R. Howe11, Thermal Radiation Heat Transfer, 2nd ed., p. 826, Hemi sphere, 1981. 